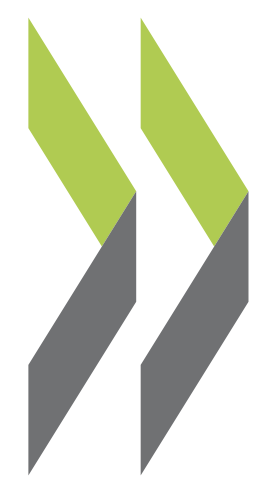

OECD Working Papers on Insurance and Private Pensions No. 37

\title{
Investment Regulations and Defined Contribution \\ Pensions
}

\section{Pablo Antolín, \\ Sandra Blome,}

David Karim,

Stéphanie Payet,

Gerhard Scheuenstuhl,

Juan Yermo 


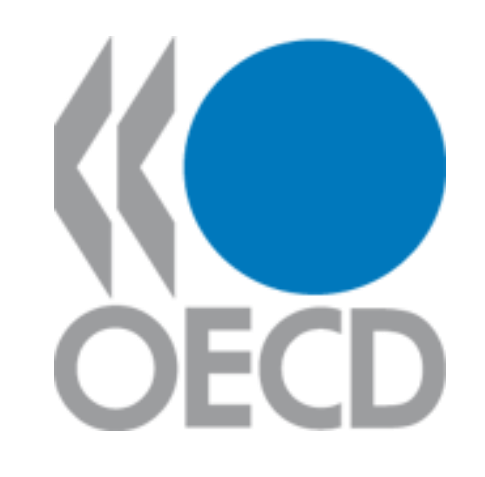

INVESTMENT REGULATIONS AND DEFINED CONTRIBUTION PENSIONS

By Pablo Antolin, Sandra Blome, David Karim, Stéphanie Payet, Jordy Peek, Gerhard Scheuenstuhl, and Juan Yermo

July 2009

OECD WORKING PAPER ON INSURANCE AND PRIVATE PENSIONS

No. 37

Financial Affairs Division, Directorate for Financial and Enterprise Affairs Organisation for Economic Co-operation and Development

2 Rue André Pascal, Paris 75116, France

www.oecd.org/daf/fin/wp 


\begin{abstract}
RÉSUMÉ
Investment regulations and defined contribution pensions

This paper assesses the impact of different quantitative approaches to regulate investment risk on the retirement income stemming from defined contribution (DC) pension plans. It looks at how such regulations affect the spectrum of investment policies available and, through this channel, how they affect the retirement income that an individual may expect from a DC pension plan.

The analysis shows that there is a trade-off between potential retirement income and protection from bad outcomes. Reducing the downside risk on retirement income from DC pension plans requires moving into relatively conservative investment policies where the share of assets allocated to bonds may be quite large. However, this comes at the cost of renouncing potentially higher replacement rates that are attainable but at a higher risk of unfavourable retirement income outcomes. Less risk adverse regulators and supervisors would aim at lower probability requirements as regard the downside risk, which will increase the range of investment policies available and thus the share of riskier assets.
\end{abstract}

JEL codes: D14, D91, E21, G11, G38, J14, J26

Key words: Investment, regulations, defined contribution pension plans, retirement income, replacement rates, risk management.

$$
\text { ****** }
$$

\title{
Réglementations en matière d'investissements et retraites à cotisations définies
}

Ce document examine l'impact de différentes approches quantitatives en matière de réglementation du risque d'investissement sur le revenu de retraite issu de plans de retraite à cotisations définies. Il étudie dans quelle mesure ces réglementations affectent le spectre des stratégies d'investissement et, par leur intermédiaire, le revenu de retraite qu'un individu peut attendre d'un plan de retraite à cotisations définies.

Cette analyse montre qu'il existe un compromis entre le revenu de retraite potentiel et la protection contre des évènements défavorables. La réduction du risque de baisse du revenu de retraite issu de plans de retraite à cotisations définies nécessite d'aller vers des stratégies d'investissement relativement conservatives, dans lesquelles la part allouée aux obligations peut être assez importante. Cependant, ceci n'est possible qu'à condition de renoncer à des taux de remplacement potentiellement plus élevés, qui ne peuvent être atteints qu'à un niveau de risque plus élevé de survenue d'évènements défavorables pour le revenu de retraite. Des régulateurs et superviseurs moins averses au risque peuvent diminuer leurs exigences en terme de probabilité du risque de baisse, ce qui augmentera la gamme des stratégies d'investissement disponibles et ainsi la part des actifs plus risqués.

Codes JEL : D14, D91, E21, G11, G38, J14, J26

Mots clés : investissement, régulation, plans de retraite à cotisations définies, revenu de retraite, taux de remplacement, gestion des risques

\section{Copyright OECD, 2009}

Applications for permission to reproduce or translate all, or part of, this material should be made to: Head of Publications Service, OECD, 2 rue André-Pascal, 75775 Paris Cédex 16, France. 


\section{INVESTMENT REGULATIONS AND DEFINED CONTRIBUTION PENSIONS}

\section{TABLE OF CONTENTS}

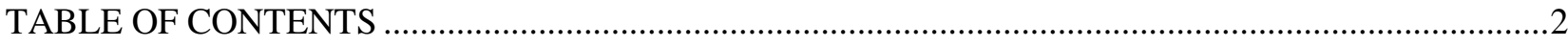

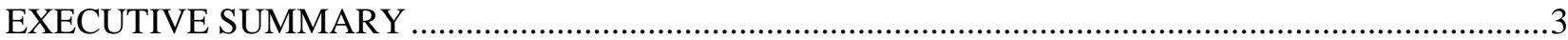

INVESTMENT REGULATIONS AND DEFINED CONTRIBUTION PENSIONS ....................................5

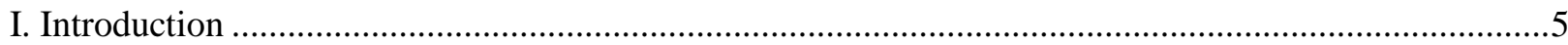

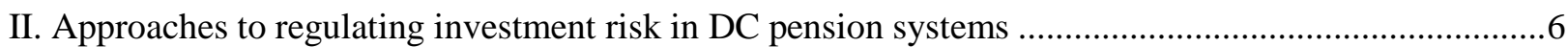

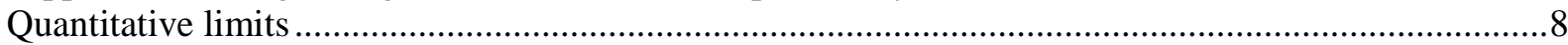

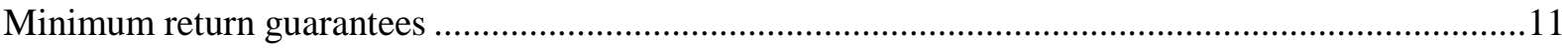

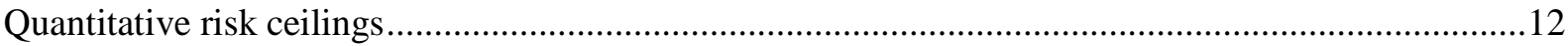

III. Modelling retirement income stemming from DC pension plans..................................................14

IV. The impact of the different regulatory approaches on investment policies available and on the

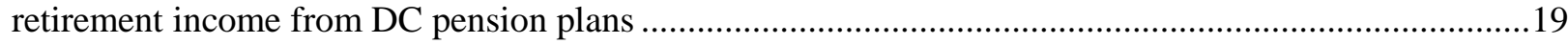

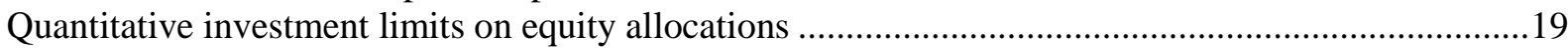

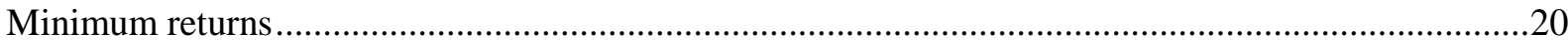

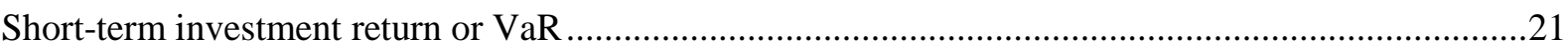

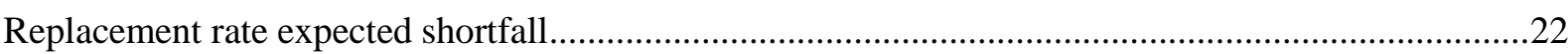

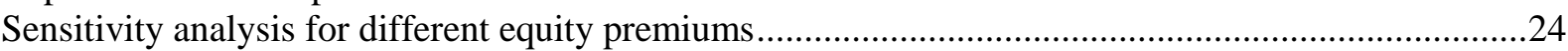

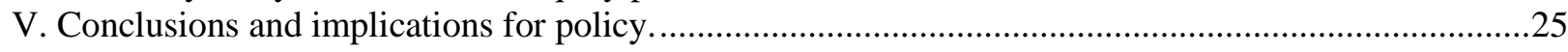

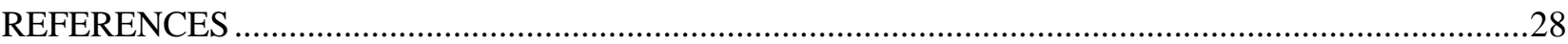

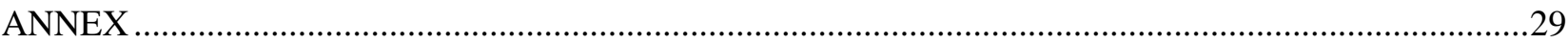

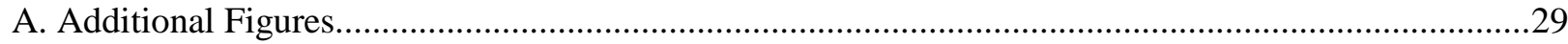

Figure A1. Mean replacement rates by level of risk as measured by the standard deviation ...................29

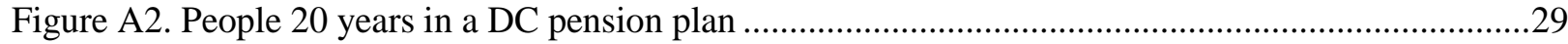

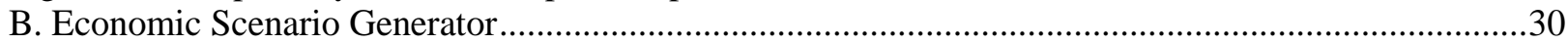

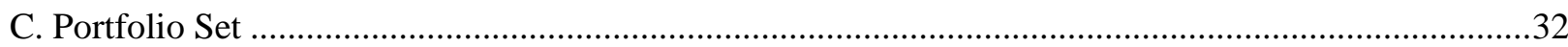

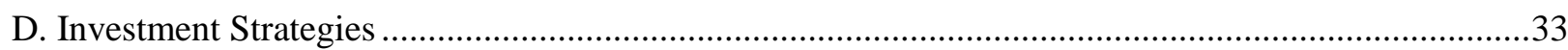




\section{EXECUTIVE SUMMARY}

The ongoing financial crisis is having a dramatic impact on individual accounts or defined contribution (DC) pension plans. Pension funds in countries with mandatory DC systems have experienced investment losses in 2008 as high as 20-25\% (Antolin and Stewart, 2009; OECD, 2009). Larger losses have been experienced by the more aggressive portfolios with high equity exposures. A collapse in the value of their pension savings is of greatest concern for workers close to retirement as well as those already in the pay-out phase that have not shifted to conservative portfolios or bought life annuities.

The crisis has happened at a time of rapid expansion of DC pensions throughout the world. Such plans are even becoming part of mandatory retirement income systems in some countries. Despite their many advantages, DC systems subject retirement benefits to a great deal of uncertainty. Regulations can be designed so as to limit some of these risks and avoid situations where older workers and retirees are exposed to major losses on their retirement income. However, designing suitable investment regulations for DC plans is a complex task. It requires careful consideration of various factors. Following a quantitative assessment of different regulations using a stochastic model of replacement rates, this paper reaches the following conclusions:

\section{$>$ The regulation of investment choice and default options in mandatory DC plans should be carefully designed}

The weight of the DC portion in total retirement income should be a key deciding factor in the design of default investment strategies. In Chile and Mexico, where the mandatory DC pension is very large in relation to total income, the default fund for a worker ten years from retirement has a maximum $20 \%$ and $0 \%$ allocation to equities, for each country respectively. In contrast, some European countries with mandatory DC systems like Estonia, Hungary and the Slovak Republic have set the conservative portfolio (with no equities) as the default for all ages. Such portfolios may be inadequate for younger cohorts as they imply lower expected retirement benefits. In Australia, the default option for the mandatory DC pension system - which provides a large part of retirement income - is not regulated, and is often in practice a balanced fund with a large equity allocation (over 60\% in some cases). In Sweden, where the mandatory DC system accounts for a very small part of total retirement income (contributions equal $2.5 \%$ of wages) the equity allocation of the default fund is even higher (around 90\%). The default equity exposures in these countries should be carefully reviewed, taking into consideration the risk that pension benefits are exposed to.

\section{$>$ In a retirement context, the risk-return trade-off of different investment portfolios and strategies should be evaluated by looking at projected retirement benefits}

This paper departs from the traditional approach to assessing investment strategies that focus on shortterm investment return and risk. In a retirement context, the objective is to maximise retirement benefits subject to a given risk level. Therefore, using a stochastic model to produce retirement income estimations, this paper maps the risk-return trade-off of different investment strategies using the replacement rate at the $5^{\text {th }}$ percentile as the risk measure and the median replacement rate as the return measure.

The analysis corroborates that an investment portfolio may be mean-variance efficient in the shortterm but inefficient when looked at through the lens of a pension plan member. Both very low allocations to equities (below 20\%) and very high ones (above 80\%) look unattractive in terms of the trade-off between replacement rate expectations and risk. In between, however, there is a wide range of options for plan members and regulators to consider. 


\section{$>$ Alternatives to conventional life-cycle investment strategies should be evaluated, especially when used as default options}

More careful analysis is also needed on the design of suitable life-cycle investment strategies, especially when used as default option. Modelling results show that a naïve life-cycle investment strategy reducing equity investment to zero over the last ten years before retirement - may not be the optimal investment strategy for an individual contributing regularly to a DC plan and intending to purchase an annuity at retirement. While life cycle strategies do indeed reduce retirement income risk they do so at the cost of lower pensions on average.

\section{> Various quantitative regulations can be established to limit retirement income risk in DC systems}

Quantitative investment regulations can be used to restrict investment policies to those that provide a certain combination of potential retirement income and risks. Risk adverse regulators and supervisors will aim at policies that reduce the downside risk or that minimise the risk of unfavourable outcomes from DC plans. Such regulations come at the cost of renouncing potentially higher replacement rates that are attainable but at a higher risk of unfavourable retirement income outcomes. Less risk adverse regulators and supervisors, on the other hand, would aim at lower probability requirements as regard the downside risk (e.g. a security level of $80 \%$ instead of $95 \%$ ), which will increase the range of investment policies available and thus the share of riskier assets.

\section{$>$ Simple quantitative regulations such as a ceiling on risky asset classes have some advantages over risk-based regulations}

Policymakers must also consider that regulations could be efficient a priori but inefficient a posteriori depending on whether real events fail to validate the modelling. They must also assess the complexity and cost of implementing and monitoring these different risk measures. Simple regulations (e.g. quantitative limit on equities) could achieve the same results than risk-based regulations (such as minimum returns, a Value at Risk (VaR) ceiling and a maximum replacement rate expected shortfall), but only in the case that the model is validated by real events. Risk-based regulations can also lead to pro-cyclical investment strategies, especially when applied over short periods.

\section{$>$ The regulatory approach should vary depending on the length of the contribution and accumulation period and the type of benefit pay-out allowed}

The impact of regulations minimising the risk of unfavourable retirement income outcomes through restrictions on investment risk depends on the length of the contribution and accumulation period. Long periods render possible investment policies with a larger share of riskier assets, increasing the potential for high replacement rates, but also risks. Short contribution periods combined with risk adverse regulators would steer people and pension funds towards conservative investment policies. The impact of different regulations is also likely to change once one considers alternatives to life annuities for the pay-out phase.

\section{$>$ The design of DC investment regulations should take into account various country-specific factors}

It is important to stress that there is not a single correct risk-retirement income trade-off to guide public policy decision. This trade off depends on the country context and on risk aversion levels. In countries where payments from DC pension plans are the main source of retirement income, the cost to the society of unfavourable outcomes are much larger than in countries where they have other sources of retirement income, such as public pension provision. Other factors such as incentives to achieve desired participation levels, cultural attitudes to financial risks and the nature of the pension promise also affect this trade-off between risk and retirement income. When participation in DC pension plan is mandatory concerns about risk may outweigh the desire to reach potentially high replacement rates. 


\title{
INVESTMENT REGULATIONS AND DEFINED CONTRIBUTION PENSIONS
}

\author{
By Pablo Antolin, Sandra Blome, David Karim, Stéphanie Payet, Jordy Peek, Gerhard \\ Scheuenstuhl, and Juan Yermo ${ }^{1}$
}

\section{Introduction}

The ongoing financial crisis is having a dramatic impact on individual account or defined contribution (DC) pension plans. Pension funds in countries with mandatory DC systems have experienced investment losses in 2008 as high as 20-25\% (Antolin and Stewart, 2009; OECD, 2009). Larger losses have been experienced by the more aggressive portfolios with high equity exposures. A collapse in the value of their pension savings is of greatest concern for workers close to retirement as well as those already in the pay-out phase that have not shifted to conservative portfolios or bought life annuities.

Policymakers throughout the world are considering possible initiatives to prevent "excessive" risk exposure in DC plans. Some countries, especially those were DC plans are mandatory, use a quantitative approach to investment regulations and in some cases limit the exposure to equities and lower this ceiling as the member reaches retirement. Age-based or life-cycle investment strategies are also increasingly popular as default options in voluntary DC systems. A few countries have gone further and imposed quantitative performance requirements on pension funds, such as minimum or target investment returns, or set limits on quantitative investment risk measures. These regulations often complement the prudent person approach that is now well extended throughout the OECD and which lays a fiduciary responsibility on pension fund managers to diversify their investment portfolios and seek the highest returns at acceptable levels of risk through a well designed investment strategy and process.

The main objective of this report is to assess the impact of different quantitative approaches to regulate investment risk on the retirement income stemming from DC pension plans. Quantitative investment regulations are common in mandatory DC systems but there are concerns about their implications for the choice of investment portfolios. This document assesses how such regulations affect the spectrum of investment policies available and, through this channel, how they affect the retirement income that an individual may expect from a DC pension plan.

The report steers clear from addressing issues related to portfolio efficiency, optimal investment strategies in a long-term or retirement planning context (Korn, 1997; Campbell and Viceira, 2002; Horneff et al, 2008) or the best approach to allocate assets accumulated in DC pension plans at retirement (Antolin, 2008, Maurer and Somova, 2009). The report addresses only regulations that directly restrict the spectrum of investment policies available for investing assets in DC pension plans,

\footnotetext{
${ }^{1}$ Mr. Antolin, Ms. Payet and Mr. Yermo are principal economist, statistical assistant and principal administrator, respectively, at the OECD, Department of Financial Affairs. Ms. Blome is an actuary in IFA-ULM. Mr. Karim, and Mr Peek are both financial engineers at Risklab, and Mr. Scheuenstuhl is managing Director of Risklab. The authors gratefully acknowledge the financial contributions of Allianz Global Investors. Comments from André Laboul, OECD, Brigitte Miksa, Allianz Global Investors, Raimond Maurer, Goethe Universitat, John Ashcroft and delegates to the Working Party on Private Pensions are gratefully acknowledged. The views expressed are the sole responsibility of the authors and do not reflect those of their organisations. The authors are solely responsible for any errors.
} 
abstracting from other regulations - such as solvency requirements - which may indirectly affect investment strategies.

The approaches to regulating investment risk in DC plans considered in this report include quantitative portfolio restrictions, minimum investment returns or targets over the whole period of accumulation (which can be interpreted also as minimum replacement rates), a maximum value-at-risk $(\mathrm{VaR})^{2}$ over a short investment period and a maximum replacement rate expected shortfall. ${ }^{3}$ The first three approaches are currently being used by regulators in some countries (e.g. minimum investment returns in Belgium, Germany ${ }^{4}$ and Switzerland, the VaR in Mexico), while the last approach is used often in an insurance context but is yet to be implemented by any country for DC pensions.

The policy objective variable used to assess the impact on retirement income of different approaches to regulate investment risk is the replacement rate, defined as the amount of pension benefits relative to the last wage, given a certain contribution rate and period.

The report, after describing the different investment regulatory approaches and their application in different countries, assesses how these different regulatory approaches affect different investment policies available, and, through them, the returns on investments and replacement rates, for a given contribution schedule in DC pension plans. Section II presents the approaches to regulating investment risk in selected OECD and non-OECD countries, focusing on those with mandatory DC systems. Section III presents a succinct explanation of the model used to assess the regulatory impact and thus help the reader through the main results discussed in section IV. The model uses a set of underlying assumptions about the statistical properties of four main asset classes (equities, bonds, property and cash), inflation and life expectancy to determine the impact of regulations on replacement rates.

The analysis shows that reducing the downside risk on retirement income from DC pension plans requires moving into relatively conservative investment policies where the share of assets allocated to bonds is quite large, generally above $60 \%$. However, this comes at the cost of renouncing potentially higher replacement rates. As a result, regulations aiming at reducing investment risks would steer pension funds and individuals to more conservative investment policies, which could be efficient $a$ priori but inefficient a posteriori if real events fail to validate the modelling. The final part of this section examines how the parameterisation of the model and in particular the underlying assumptions about market returns affect outcomes (e.g. the equity premium). This sensitivity analysis on the return assumptions confirms the robustness of the main message. Section V concludes with some policy recommendations.

\section{Approaches to regulating investment risk in DC pension systems}

Policymakers take different approaches to the regulation of the investment risks to which pension funds are exposed. The approach taken naturally depends on the type of pension system which is being supervised (e.g. whether defined benefit or defined contribution schemes are involved, whether the system is mandatory or voluntary etc.), the broader country context in which the pension funds are

\footnotetext{
${ }^{2}$ Value at Risk is a statistical measure defined as the maximum tolerable loss on an investment portfolio that could occur with a given probability (e.g. 5\%) within a given period of time.

${ }^{3}$ In an investment context, the expected shortfall is a statistical measure defined as the expected return on the portfolio in the worst cases that could occur with a certain probability (e.g. 5\%) within a given period of time. The expected shortfall is also called Conditional Value at Risk or Expected Tail Loss.

${ }^{4}$ Private pensions in Belgium and Germany are generally classified as of defined benefit type because by law sponsoring employers are responsible for the minimum return guarantees. Nevertheless, this paper will refer to these countries when talking about such guarantees.
} 
operating (e.g. how developed are the capital markets, how financially literate are pension fund members and beneficiaries etc.), and the regulatory approach (greater or lesser use of quantitative rules as opposed to a "pure" prudent person approach).

In defined contribution systems, a key concern of policymakers is that individuals - for a variety of reasons - may be exposed to excessive investment risk, raising the possibility that pension benefits may be significantly below expectations. Such concerns are enhanced in private pension systems that provide a large part of workers' retirement income, which is often the case in countries where the systems are mandatory, but also in some countries, like Ireland, the United Kingdom and the United States, where private pensions are voluntary. ${ }^{5}$ The larger the DC system is in relation to public pensions, the greater is an individual's need for predictability and security of the DC portion. Governments may also be exposed to explicit or implicit liabilities in such systems, as they may be expected to help those whose pension benefits fall below a certain level.

Policymakers can address investment risk in two main ways: they can design regulations that affect pension fund member's investment choices and default options and they can directly regulate the investment decisions of pension fund managers. This section reviews the country evidence on both types of regulations.

Following OECD recommendations, investment regulations need to be based on a prudent person standard, which focuses on qualitative aspects of the process of investment management. ${ }^{6}$ The recommendation also acknowledges the use of quantitative forms of investment regulation, and in particular, quantitative investment restrictions, as a complement to the prudent person standard. Many countries with mandatory DC systems rely on quantitative investment restrictions to limit the extent of investment risk that pension funds are exposed to. Such countries include for example Chile and Colombia outside the OECD area, and Hungary, Poland and the Slovak Republic within the OECD (Table 1).

While investment limits are by far the most popular form of quantitative investment regulations, there are two other types used by policymakers. One consists in requiring pension funds to meet a minimum investment return set in absolute terms (e.g. 2.75\% as in Switzerland). ${ }^{7}$ The second option consists in setting quantitative risk limits on the overall pension fund portfolio. For example in Mexico, pension fund investments are subject to a VaR ceiling, while in Denmark, the mandatory ATP fund and the pension funds that operate in the quasi-mandatory system are subject to stress tests on the investment return guarantees they offer. ${ }^{8}$

\footnotetext{
${ }^{5}$ Workers entering the workforce in any of these three countries are most likely to be offered a DC plan by their employers.

${ }^{6}$ OECD (2005), Guidelines on Pension Fund Asset Management

${ }^{7}$ Some countries with voluntary pension fund systems (e.g. Belgium, Germany) also set minimum investment returns. The Austrian government is also considering reintroducing minimum return requirements.

${ }^{8}$ Stress tests involve scenario simulations. For example a regulator's stress test may simulate a $20 \%$ drop in equity prices and determine the likely impact of such scenario on the pension fund solvency status.
} 
Table 1. Investment regulation in mandatory DC pension systems in OECD and selected non-OECD countries

\begin{tabular}{|l|c|c|c|}
\hline \multicolumn{1}{|c|}{ OECD } & $\begin{array}{c}\text { Quantitative investment } \\
\text { restrictions by asset class }\end{array}$ & $\begin{array}{c}\text { Minimum investment } \\
\text { return (absolute) }\end{array}$ & $\begin{array}{c}\text { Quantitative } \\
\text { risk limits }\end{array}$ \\
\hline Australia & & & \\
\hline Denmark & $\checkmark$ & & $\checkmark$ \\
\hline Hungary & $\checkmark$ & & $\checkmark$ \\
\hline Mexico & $\checkmark$ & & \\
\hline Poland & $\checkmark$ & & \\
\hline Slovak republic & $\checkmark$ & & \\
\hline Sweden & $\checkmark$ & & \\
\hline Switzerland & $\checkmark$ & & \\
\hline \multicolumn{1}{|c|}{ Non-OECD } & $\checkmark$ & & \\
\hline Chile & $\checkmark$ & & \\
\hline Colombia & $\checkmark$ & & \\
\hline Estonia & $\checkmark$ & & \\
\hline Israel & $\checkmark$ & & \\
\hline Russian Federation & & & \\
\hline
\end{tabular}

Note: non-OECD countries include only those that are observers to the OECD Working Party on Private Pensions.

\section{Quantitative limits}

In recent years, many OECD countries have relaxed quantitative investment restrictions. At the end of 2007 around one-half of OECD countries limited pension fund investments in certain asset classes, most frequently equities and foreign securities. However, the limits are generally set at high levels, and, with a few exceptions, there is little evidence that they are binding, that is actually restricting investment allocations. For example, Figure 1 shows that pension fund equity limits appear to be binding in Norway and Poland. In most other countries, direct investment in equities (excluding indirect investment via mutual funds) is substantially lower than the statutory ceiling. 
Figure 1. Portfolio limits on OECD pension funds' investment in equities, 2007

As a percentage of total investment

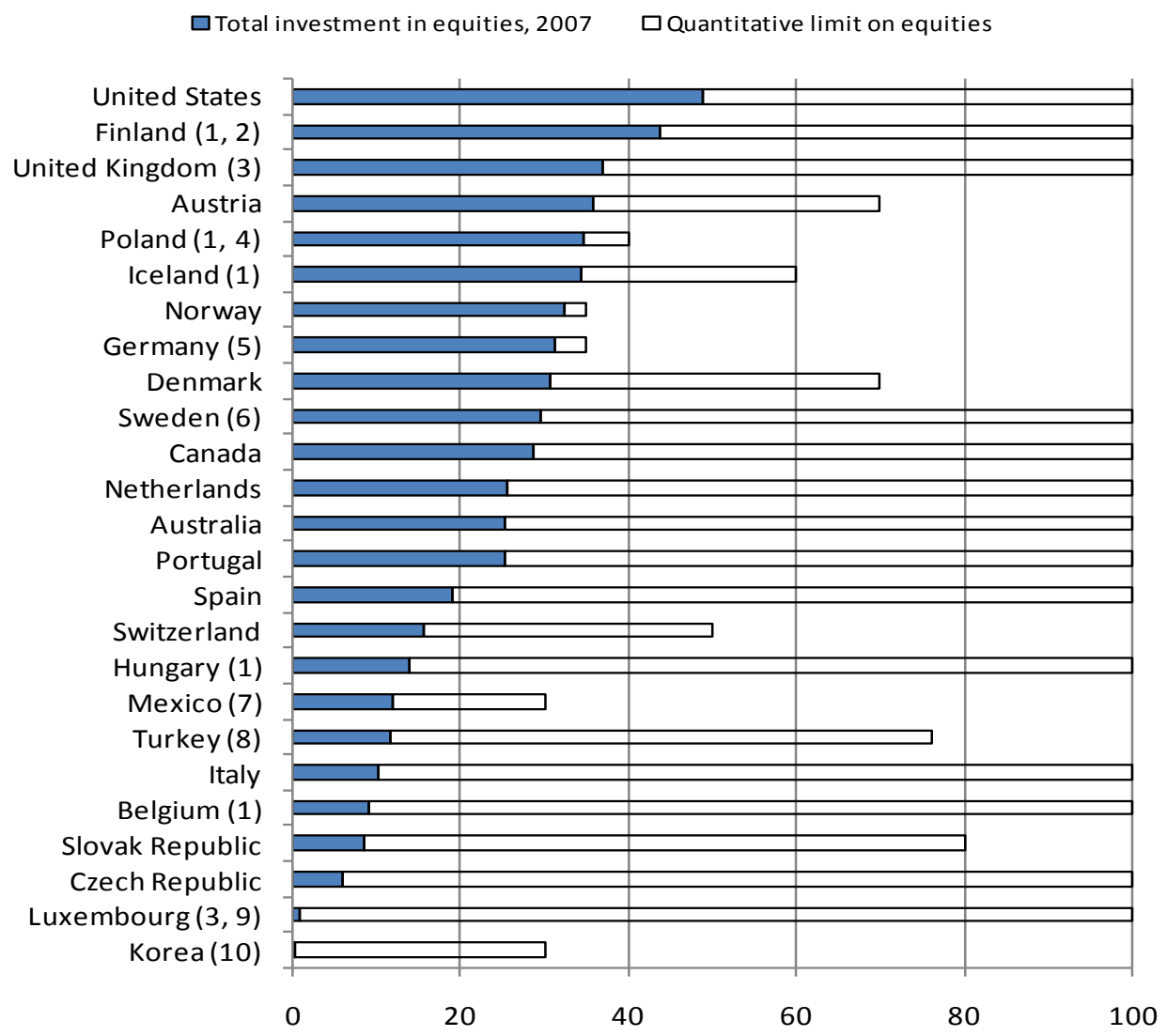

Notes: (1) Investment limit refers to listed equities; (2) Investment limit refers to statutory pension plans; (3) Data refer to the year 2006; (4) Investment limit refers to mandatory personal pension plans; (5) Investment limit refers to Pensionskassen (pension institutions); equity investments are probably overstated due to the inclusion of investments in mutual funds that should be broken down and reallocated both to equity and bond investments; (6) Pension foundations are not subject to uniform investment rules and are not, therefore, covered here; (7) Investment limit refers to Basic Fund 5; (8) Data only refer to personal pension plans; (9) Investment limit refers to ASSEP and SEPCAV; and (10) Investment limit refers to corporate DB plans.

Source: OECD Global Pension Statistics.

The situation in both OECD and non-OECD countries that have introduced mandatory, "pure" ${ }^{99}$ DC systems is rather different as nearly all make use of quantitative portfolio limits. Some of these restrictions were often much stricter when the systems were first established. For example, Chile prohibited equity investments until 1985 and foreign investment until 1998. Similarly, pension funds were initially not allowed to be invested in foreign assets in Colombia and Mexico, but these restrictions have since been relaxed.

Most of these countries have also introduced portfolio choice and set limits that are specific to each fund option. The specific limits are shown in Table 2, arranged by equity exposure. The choice of fund is restricted depending on the age of the participant in Latin American countries (Chile, Colombia, Mexico). For example, in Chile, pensioners may only choose the options with an equity ceiling of at most $40 \%$ (options 3 to 5 in Table 2), while participants who are 10 years from retirement or less may choose the options with an equity allocation of at most $60 \%$ (options 2 to 5 in Table 2). The default

\footnotetext{
${ }^{9}$ By "pure" DC we mean those systems that do not provide absolute return guarantees or benefit promises. Compared to Table 1, Table 2 excludes Denmark and Switzerland.
} 
option for members who do not make a choice also depends on the age of the participant, with older workers assigned to the options with a lower equity allocation. For example, in Chile, participants who are ten years from retirement and pensioners are assigned by default to the fund which has up to $20 \%$ in equities (option 4 in Table 2). In Mexico, workers with ten years from retirement are assigned by default to the fund with no equity exposure (option 5 in Table 2).

By contrast, European countries (Estonia, Hungary, Slovak Republic) do not apply any restrictions on the choice of fund and have a single default option for all - irrespective of age - which is the one with no equities (Estonia and Slovak Republic) or a small allocation to equities (10\% in Hungary).

As shown in Table 2, there are also some countries that do not allow fund choice (Colombia, Israel, Poland, and the Russian Federation), while others do not regulate fund choice, allowing each provider to establish choices at their own will and letting individuals freely choose among the portfolio options offered by providers (Australia and Sweden). Australia also has no regulated default fund, but as the system is mandatory employers must allocate workers to one of the options available. Most employers in Australia use "balanced" funds - with approximately $45-65 \%$ in equities - as default options. ${ }^{10}$ Sweden, on the other hand, has a statutory default fund option, managed by the state-controlled reserve fund AP7, which is largely invested in an internationally diversified equity portfolio (over 90\% of assets).

Table 2. Equity investment limits by type of fund option in OECD and selected non-OECD countries that have mandatory "pure" DC systems (options arranged by decreasing equity exposure)

\begin{tabular}{|c|c|c|c|c|c|}
\hline & Option 1 & Option 2 & Option 3 & Option 4 & Option 5 \\
\hline \multicolumn{6}{|l|}{ OECD } \\
\hline Australia & \multicolumn{5}{|c|}{ Fund choice is not regulated } \\
\hline Hungary & $100 \%$ & $40 \%$ & \multicolumn{3}{|c|}{$10 \%$} \\
\hline Mexico & $30 \%$ & $25 \%$ & $20 \%$ & $15 \%$ & $0 \%$ \\
\hline Poland & \multicolumn{5}{|c|}{ No fund choice } \\
\hline Slovak republic & $80 \%$ & $50 \%$ & \multicolumn{3}{|c|}{$0 \%$} \\
\hline Sweden & \multicolumn{5}{|c|}{ Fund choice is not regulated } \\
\hline \multicolumn{6}{|l|}{ Non-OECD } \\
\hline Chile $^{1}$ & $40 \%-80 \%$ & $25 \%-60 \%$ & $15 \%-40 \%$ & $5 \%-20 \%$ & $0 \%$ \\
\hline Colombia & \multicolumn{5}{|c|}{ No fund choice } \\
\hline Estonia & $50 \%$ & $25 \%$ & \multicolumn{3}{|c|}{$0 \%$} \\
\hline Israel & \multicolumn{5}{|c|}{ No fund choice } \\
\hline Russian Federation & \multicolumn{5}{|c|}{ No fund choice } \\
\hline
\end{tabular}

Notes: non-OECD countries include only those that are observers to the OECD Working Party on Private Pensions. (1) In Chile, equity investments in each fund option are subject to both a floor and a ceiling.

Portfolio choice and default options tend to be less regulated in voluntary DC systems. ${ }^{11}$ For example, no OECD country with a voluntary DC system has established specific investment options that providers must offer and only a few regulate default options. Since 2007, for example, DC providers in the United States can assign undecided workers to one of four possible default options laid out in a 2007

\footnotetext{
${ }^{10}$ See Tapia and Yermo (2007)

${ }^{11}$ See Ascroft (2009).
} 
Department of Labor ruling. ${ }^{12}$ The qualified default options all involve moving to more conservative investment allocations in the years running up to retirement. One of them is target (retirement) date funds, which follow a lifestyle investment strategy reducing the equity allocation as the target date approaches, the target date being understood as the individual's retirement age. However, the specific equity allocation of target date funds is not regulated, and some funds have as much as $60 \%$ invested in equities at the target date.

By contrast, life-styling investment is required in UK stakeholder pensions (a type of DC scheme) and is common also for trust-based DC plans. At least within the last five years before a member's retirement date, the assets in the default fund should be gradually transferred into interest bearing deposits or government securities so as to reduce the member's exposure to volatility. This investment restriction is to some extent consistent with purchasing a life annuity before age 75 with at least $75 \%$ of the accumulated balance. ${ }^{13}$ The rest can be withdrawn as a lump-sum at retirement.

Ireland has implemented a regulation that has led to universal use of life-styling investment strategies in Personal Retirement Savings Accounts (PRSAs). PRSAs are subject to a regulatory actuarial prudence requirement, which has been interpreted by providers as calling for life-cycle investment strategies. On the other hand, few trust-based DC plans use life-styling, with the typical default fund being as much as $65-80 \%$ invested in equities. As in the United Kingdom, the preference for life-styling is driven by annuitisation requirements.

\section{Minimum return guarantees}

Only a few countries with mandatory DC systems require pension funds to meet minimum investment returns, and in most cases, these minimum returns are "relative", as they are set in relation to the pension fund industry's average rate of return over a certain period, usually a few months (e.g. Chile, Poland, and the Slovak Republic). For example, in Chile the minimum guarantee is based on the average real rate of return for all pension funds over the previous 36 months. It is 50 percent of that average or 2 percentage points less than the average, whichever is lower. If the rate of return received by a fund falls below that minimum, the worker's pension account is credited with the minimum rate rather than the actual rate of return.

Of all the countries shown in Table 1 the only country that applies an absolute rate of return guarantee is Switzerland, where pension funds must meet a minimum investment return of $2.75 \%$ in nominal terms. The guarantee must be applied both when an employee changes job and at retirement. Pension funds strive to pay returns above the minimum, but they do not have to and they usually only credit individual accounts with the guaranteed return, saving any excess as a reserve.

Adverse market conditions have led the government to reduce the guarantee in recent years. The guaranteed return was $4 \%$ until January 2003 when it was lowered to 3.25\%. In January 2004 it was further reduced to $2.25 \%$. As a result of the current financial turmoil, the government is once again considering a reduction in the minimum return that pension funds must guarantee, from the current $2.75 \%$ to $2 \%$ in 2009 .

Minimum absolute return requirements are also rare in voluntary DC systems. Two countries that apply them are Belgium and Germany while Austria is considering reintroducing it. Sponsoring employers of DC pension plans in Belgium must since January 2004 guarantee an annual minimum return of $3.75 \%$ on employees' contributions and $3.25 \%$ on their own contributions. The actual market

${ }^{12}$ Examples of the four qualified default options are (i) a life-cycle or target date fund, (ii) a professionallymanaged account, (iii) a balanced fund, and (iv) a capital preservation product for only the first 120 days of participation.

${ }^{13}$ There is not a requirement to buy an annuity before age 75 as people can chose to purchase an annuity or to go into alternatively secured pensions where the money remains invested but there is income draw down. 
return must be applied to the individual account if this is higher than the minimum. In Germany, sponsors of the new Riester pensions must guarantee capital preservation of contributions at retirement and when an employee switches plan. This guarantee is equivalent to a minimum $0 \%$ nominal rate of return.

Absolute return guarantees such as the one in place in Belgium effectively eliminate any possibility of bad investment returns translating into lower benefits for plan participants. On the other hand, such guarantees force pension funds to invest in a cautious manner in order to avoid having to cover any return shortfall with additional contributions from employers (or employees). It is also difficult for governments to decide on a suitable return guarantee that pension funds can meet, as has been observed in Switzerland.

\section{Quantitative risk ceilings}

Pension funds in some OECD countries have introduced quantitative measures and simulation exercises to assess the level of investment risk which funds are exposed to via their portfolio holdings. Risk measures come in two main types. ${ }^{14}$ An "overall risk measure" takes into account both positive and negative outcomes, measuring the "distance" between the risky situation and the corresponding risk-free situation. A "downside risk measure", on the other hand, focuses only on the negative outcomes.

The standard overall risk measure in the finance literature is the standard deviation or variance. Investment strategies based on the Capital Asset Pricing Model (CAPM) developed by Sharpe (1962) rely on this measure as the basic counterpart to the mean return in order to identify efficient portfolio allocations. The standard mean-variance model of Markowitz (1952) which lies at the heart of the CAPM, however, has some serious drawbacks for long investment horizons. As it is a one period model, the mean-variance model fails to recognise the variability of investment opportunities and specifically the volatility of the short term interest rate. Recent modelling of inter-temporal portfolio decisions recognises that the risk-free for a long term investor is usually a default-free inflation-indexed bond (Campbell and Viceira (2002)).

The main downside risk measure is the so-called value-at-risk or VaR. VaR is defined as the maximum loss in a portfolio with a given probability or confidence interval (typically 5\%) and over a given planning horizon. VaR can provide the fund manager and the supervisor with a summary measure of market risk to which each pension portfolio is exposed. This single number summarizes the portfolio's exposure to market risk as well as the probability of an adverse move. The in-house investment managers or the pension regulator can then decide whether they feel comfortable with this level of risk. If the answer is no, the process that led to the computation of VaR can be used to decide where to trim risk. For instance, the riskiest securities can be sold, or derivatives such as futures and options can be added to hedge the undesirable risk. VaR also allows users to measure incremental risk, which measures the contribution of each security to total portfolio risk.

The main attraction of the $\mathrm{VaR}$ is that it provides a common measure of risk across different positions and risk factors. However, it does not consider losses or gains when the bad state does not occur nor does it say anything about the expected loss when the bad state occurs. This is particularly problematic if return distributions have "fat tails", that is, very negative outcomes that occur with a larger probability than in normal distributions. The $\mathrm{VaR}$ is used in banking to measure daily risk exposures, but it is less wide spread among pension funds. The horizon question is also important here. Basically VaR in Basel type banking is centred on a zero mean while a pension scheme needs to be concerned with non-zero means to the return distribution.

Another downside risk measure is the expected shortfall which is the average of the worst losses. This measure is used by insurance companies to estimate the mean size of losses above a certain

\footnotetext{
${ }^{14}$ See Dhaene et al (2003).
} 
threshold. It is also relatively easy to estimate as the actuary simply generates a large number of loss scenarios and then takes the expected shortfall as of the largest losses with a given probability.

A related approach to measuring downside risk involves simulating specific loss scenarios or stress testing. This approach applies specific declines in values to assets to see if the portfolio could meet certain requirements under these conditions (if not evasive action is required within a certain time frame). The tests seek to quantify the expected loss in a given (adverse) scenario and to act as an 'early warning system', proactively tackling potential problems in order to prevent debilitating investment losses from occurring. But scenario testing suffers the drawback that we do not know the likelihood of the event only the consequence.

In some countries pension funds provide guaranteed returns or benefits for their members, either in the form of defined benefit pensions or defined contribution schemes with some form of minimum return. Supervisory authorities in these countries apply solvency requirements to ensure that the pension funds have sufficient assets to meet these guarantees. Stress test measures the strength of these solvency margins under different investment conditions.

Risk measures such as the VaR and the expected shortfall and stress testing can be a useful way for pension supervisory authorities to assess the level of investment risk to which pension funds are exposed, testing the sensitivity of investment portfolios to extreme fluctuations in market conditions. They may therefore allow for timely preventive action to protect pension assets from market risks. Using downside risk measures also allow the supervisor to integrate the impact of derivatives on portfolio returns and risks.

However, the tools used in such testing and their application to pension funds do not come without criticisms. These methods were designed for solvency assessments of banks - institutions with shortterm horizons and exposed to potential liquidity scares. Whether they are appropriate for pension funds - which are long-term investment vehicles - needs to be considered. Problems may therefore arise when applying such tests to pensions - including inadvertently forcing pension funds to invest in assets which may offer too low risk and return over a long-term horizon, which may not adequately match a pension fund's liabilities. They may also cause negative feedback loops in pricing and investment, forcing pension funds into assets - such as bonds - whose prices are artificially inflated by their excess demand, which in turn magnifies solvency problems - via lower discount rates-, heightening the demand for those assets. The tests could therefore potentially impose too high a 'cost' on pension fund returns for the outside risks which they are designed to cover. The actual costs of designing the testing models also need to be considered, as these ultimately have to be borne by either the supervisor or the pension funds themselves.

The only example so far of a country that has implemented a VaR type of regulation in a "pure" DC system is Mexico. The pension fund supervisor, CONSAR, has established indicators to measure investment risks. It traditionally used quantitative portfolio limits, but the current focus is on Value at Risk (VaR) calculations. ${ }^{15}$

CONSAR has adopted VaR as one of its daily methods and measures used for risk supervision. For VaR purposes, it takes a one day horizon for the total portfolio, and estimates the VaR using the historic returns over the past 500 day period. The confidence interval is $95 \%$; that is there is a $95 \%$ probability that the actual returns will be within the range of expected returns, i.e. with only a $2.5 \%$ probability that the actual return will be worse than the VaR (figure 2). Stress testing is also done by type of asset. This examines the effect of simulated large movement in key risk factors upon the value of the portfolio, via conditional probability models which take account of risk factors correlations. Until 2007, CONSAR required that the VaR could not be higher than $0.60 \%$ of the total assets of the pension fund (the Siefore). In other words, the maximum permitted VaR for a fund of $\$ 1$ billion was $\$ 6$ million. Since

\footnotetext{
${ }^{15}$ The VaR approach coexists with quantitative restrictions.
} 
2007, this VaR limit applies to the most conservative investment option (with no equities), while the four new alternative investment portfolios are subject to VaR limits that increase with the limit set for equities. The riskiest investment option is subject to a $30 \%$ equity ceiling and a $2 \%$ daily VaR limit.

Figure 2.

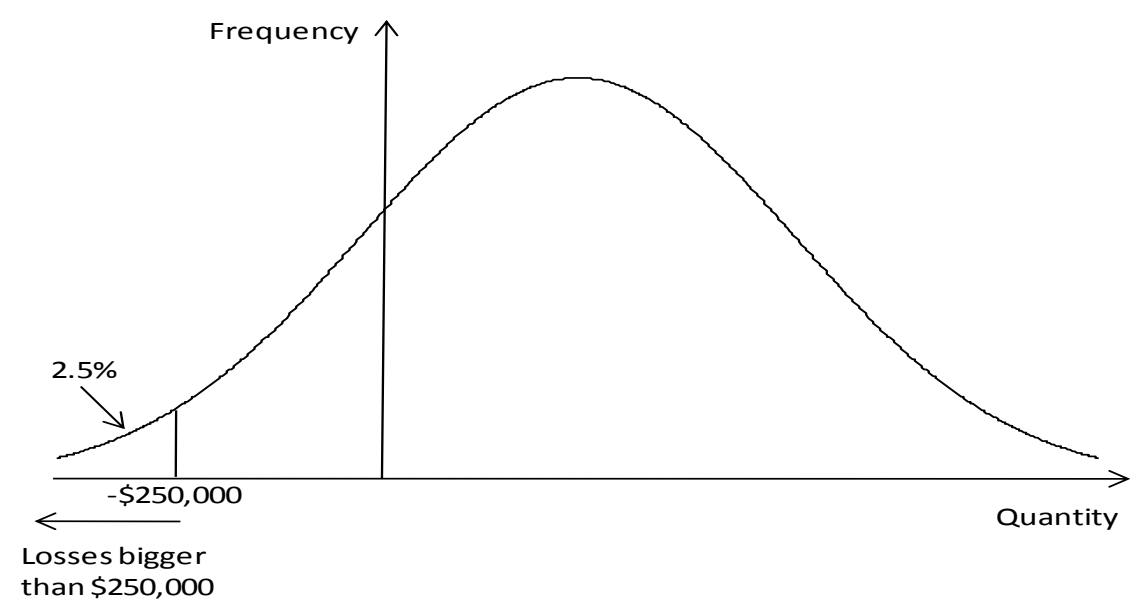

\section{Modelling retirement income stemming from DC pension plans.}

This section succinctly describes the model used to calculate the retirement income an individual could expect to achieve at retirement in a DC pension plan given different investment policies. ${ }^{16}$ The model produces stochastic simulations of the replacement rate given simulations on investment returns, inflation and life expectancy. This is the model that the next section uses to assess the impact of different regulation to reduce investment risk on the adequacy of retirement income for a given scheduled contribution and risk profile.

The model uses the replacement rate -- the ratio of income after retirement to income just before retirement -- to assess the adequacy of retirement income an individual could expect from a DC pension plan for different investment policies. The replacement rate is calculated as the ratio of the annuity income that the value of assets accumulated in a DC plan can yield at retirement to the wage just before retirement.

The value of the assets accumulated in a DC pension plan at retirement depends primarily on the contribution rate, the length of the contribution period and the investment policy followed. The model assumes that people contribute $10 \%$ of wages each year ${ }^{17}$ to their DC plan and wages grow, from an initial wage of 10,000 currency units, by $3.785 \%$ on average annually, according to a stochastic inflation rate with median $2 \%$ and a fixed productivity growth of $1.75 \%$ annually. ${ }^{18}$ The value of accumulated assets is calculated for two different holding periods of 40 and 20 years. As the retirement age is set at age 65, those two accumulation periods are equivalent to people joining a DC pension plan at age 25 (an ideal age to begin saving for retirement) and at age 45 . Given the contribution rate and the contribution

\footnotetext{
${ }^{16}$ The annex describes the modelling in more detail.

${ }^{17}$ Fixed contribution rates are common in mandatory DC systems. However, a different contribution schedule could be for contribution rates to increase with the age of the individual, as is the case in Switzerland, for example. The trade-offs between risk and expectations presented are not affected by the choice of contribution rate.

${ }^{18}$ The model abstracts from issues related to human capital risk. The wage profile does not reflect a fall in wages at old ages but it continues growing through the working life of an individual. Using different wage profiles does not affect the results discussed herein.
} 
period, and following the standard asset accumulation formula, the main unknown variable left is the rate of return on the investment portfolio.

Contributions to DC plans are invested in various portfolios containing different initial allocations of four asset classes -- cash, bonds, equities and property. The basic statistical properties of the asset classes (mean, standard deviation and correlation) are based on historical data. The mean and standard deviations of the asset classes, as well as the correlation matrix, are shown in Table 3. The initial portfolio allocations considered are show in table 4 . The choice of only four highly aggregated assets classes (e.g. bonds could have been split into government and corporate bonds), and of eleven ad-hoc asset allocations intend to reflect the basic assets classes and portfolio allocations available in a typical DC system. The proposed portfolio allocations are also mean-variance efficient in a one-period (month) context. ${ }^{19}$ This simplification of the investment choice problem facilitates the examination of the impact of regulation on replacement rates. ${ }^{20}$

Table 3. Mean standard deviation and correlation matrix of the different asset classes

\begin{tabular}{llccc} 
& & Return & Volatility & \\
\cline { 3 - 4 } & Cash & $4.0 \%$ & $2.0 \%$ & \\
& Bonds & $5.5 \%$ & $4.5 \%$ & \\
& Equity & $7.5 \%$ & $15.0 \%$ & \\
& Property & $6.0 \%$ & $10.0 \%$ & \\
\cline { 2 - 4 } & \multicolumn{3}{c}{ Correlation Matrix } \\
\cline { 2 - 4 } Cash & Cash & Bonds & Equity & Property \\
\cline { 2 - 4 } Bonds & $100.0 \%$ & & & \\
Equity & $20.0 \%$ & $100.0 \%$ & & \\
Property & $0.0 \%$ & $0.0 \%$ & $100.0 \%$ & \\
\hline
\end{tabular}

Table 4. Portfolio allocations

\begin{tabular}{lcccc} 
& Cash & Bonds & Equity & Property \\
\cline { 2 - 5 } Portfolio 1 & $5.0 \%$ & $85.0 \%$ & $0 \%$ & $10 \%$ \\
Portfolio 2 & $5.0 \%$ & $75.0 \%$ & $10 \%$ & $10 \%$ \\
Portfolio 3 & $0.0 \%$ & $71.0 \%$ & $20 \%$ & $9 \%$ \\
Portfolio 4 & $0.0 \%$ & $65.0 \%$ & $30 \%$ & $5 \%$ \\
Portfolio 5 & $0.0 \%$ & $58 \%$ & $40 \%$ & $2 \%$ \\
Portfolio 6 & $0.0 \%$ & $50 \%$ & $50 \%$ & $0 \%$ \\
Portfolio 7 & $0.0 \%$ & $40 \%$ & $60 \%$ & $0 \%$ \\
Portfolio 8 & $0.0 \%$ & $30 \%$ & $70 \%$ & $0 \%$ \\
Portfolio 9 & $0.0 \%$ & $20 \%$ & $80 \%$ & $0 \%$ \\
Portfolio 10 & $0.0 \%$ & $10 \%$ & $90 \%$ & $0 \%$ \\
Portfolio 11 & $0.0 \%$ & $0.0 \%$ & $100 \%$ & $0 \%$ \\
\hline
\end{tabular}

19 The 11 portfolio allocations are mean-variance efficient (in a Markowitz sense) subject to a maximum investment in cash of $5 \%$.

${ }^{20}$ Discussing the type of assets that need to be considered to design an efficient long-term investment portfolio pertains to the literature on optimal portfolio allocation, which is beyond the scope of this paper. 
Each of these 11 portfolios is managed over time according to 3 different investment strategies, fixed portfolio, dynamic risk budget, and life cycle. This results in 33 investment policies and the model calculates the replacement rate for each of these investment policies. These investment strategies are as follows: ${ }^{21}$

- Fixed portfolio allocation: the portfolio allocation is adjusted back or rebalanced to the initial allocation at the end of every period (i.e. month).

- Dynamic risk budget: each portfolio is allowed to change its asset allocation according to its risk budget. Portfolios with a larger risk budget can be more aggressive in their investment strategy. The changes in allocation are limited to $20 \%$ both above and below the initial allocation in equities. Reallocations occur monthly.

- Life cycle: in the last 10 years before retirement, the initial allocation of the portfolio changes into more defensive portfolios to reduce the volatility of the asset returns. This is achieved by reducing the individual exposure to equities in each of the 11 portfolios $10 \%$ starting 10 years before retirement so as to have $0 \%$ allocated in equities the year before retiring (Portfolio 1 in Table 4).

Pension benefits are calculated assuming that the whole accumulated balance at retirement is transformed into a life annuity priced at market rates by insurance companies. The model abstract from different choices of allocating assets at the payout phase (e.g. programmed withdrawal, variable annuities); it just allows for a standard fixed value life annuity bought at the time of retirement. ${ }^{22} \mathrm{~A}$ stochastic annuity rate is used to transform the balance in the individual account into a fixed monthly payment paid until the plan member dies. The annuity rate takes into account life expectancy and the level of interest rate at retirement. The ratio of this annuity income to the wage just before retiring is the replacement rate measure. ${ }^{23}$

The main outcome of the modelling exercise is a probability distribution function of the replacement rate an individual could expect to achieve at retirement for joining a DC pension plan given those 33 different investment policies (figure 3 ). The model assumes that returns to each asset class, inflation and life expectancy are stochastic. Therefore, it produces 10,000 stochastic simulations for the investment returns of each underlying asset class. Consequently, the model generates 10,000 simulations of the value of the assets accumulated in a DC plan - the lump-sum at retirement from a DC plan - for each of the resulting 33 investment policies. Finally, given stochastic life expectancy ${ }^{24}$ and different stochastic interest rate simulations, it obtains an annuity factor that applied to the value of the assets accumulates produces 10,000 stochastic simulations of the replacement rate for each of the investment policies. The 10,000 Monte Carlo simulations provide a distribution function of the replacement rate for each of the 33 investment policies. Figure 3 shows the probability distribution of one investment policy. Having a probability distribution allows calculating the mean, median, the standard deviation and the different percentiles, in particular the 5th and the 95th percentile.

The analysis and discussion of the results below uses the median instead of the mean to assess the replacement rate stemming from each investment policy, and it uses the $5^{\text {th }}$ percentile instead of the

\footnotetext{
${ }^{21}$ These investment strategies are described in more detail in the Annex, section D.

${ }^{22}$ See Antolin (2008) for different options to allocate assets accumulated in DC pension plans. Current work in progress by the authors focuses, among other, on relaxing this assumption.

23 As the replacement rate is measured at retirement only, the model abstracts from inflation risk during the remainder of the life of the individual. The relative impact on benefits of different investment portfolios, strategies and regulations would not change significantly if post-retirement inflation is also considered in the model.

${ }^{24}$ Stochastic life expectancy is calculated using the Lee-Carter model as set up in Antolin (2007).
} 
standard deviation as a measure of the risk associated with the replacement rate. The replacement rate corresponding to the $5^{\text {th }}$ percentile indicates that $95 \%$ of the replacement rates an individual could expect to achieve with that specific investment policy are above that rate. Another interpretation of the $5^{\text {th }}$ percentile is that 95 out of every 100 cohorts of plan members would get a replacement rate higher than this minimum level. ${ }^{25}$ Five out 100 cohorts would be expected to get a replacement rate below the $5^{\text {th }}$ percentile.

Figure 3 shows that the distribution function is skewed to the right. As a result of the skewness of the distribution, the mean is always higher than the median. Therefore, the probability of achieving a replacement rate equal to the mean is less than $50 \%$. In the same way, the $5^{\text {th }}$ percentile is a more appropriate measure of risk than the standard deviation. ${ }^{26}$ This is particularly the case if one considers plan members' and regulators' aversion to very low replacement rates.

Figure 3. Example of a distribution function of replacement rates

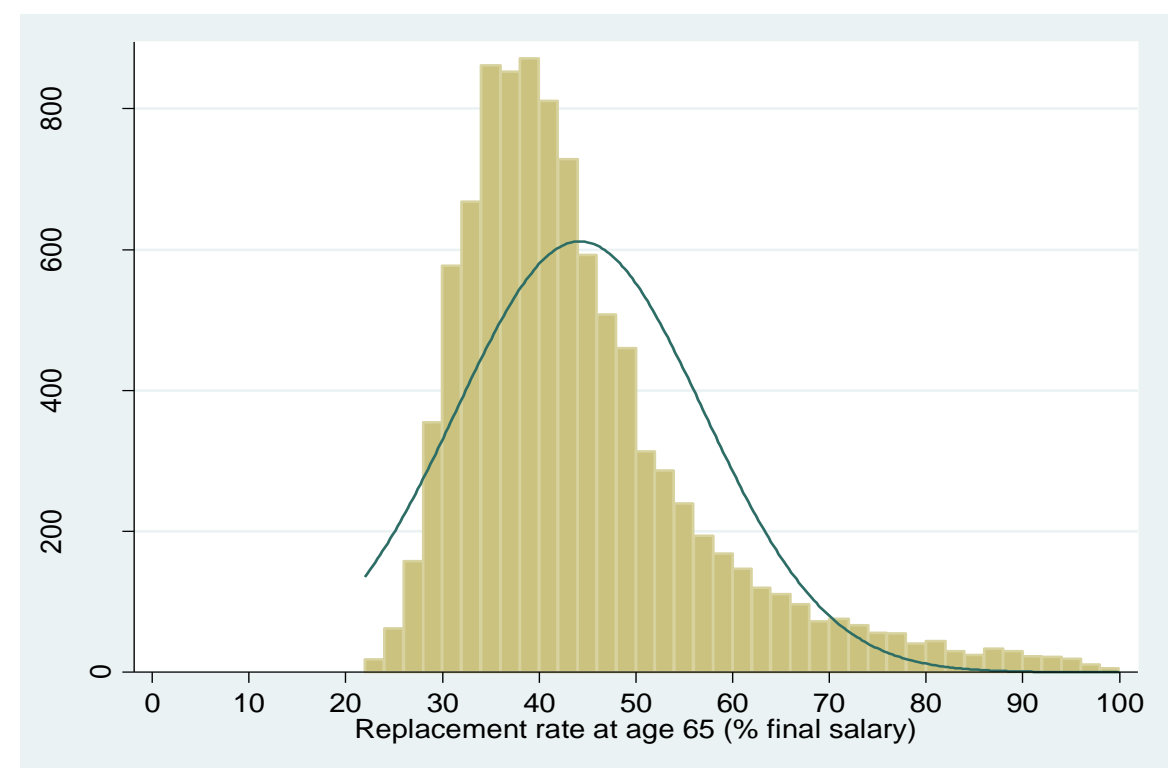

Note: Replacement rates for people joining the labour market at age 25 , contributing $10 \%$ of wages and working continuously for 40 years.

Figures 4 and 5 report the median replacement rate by the level of risk, measured by the $5^{\text {th }}$ percentile, for each portfolio and investment strategy for people contributing and accumulating assets in a DC pension plan during 40 years. ${ }^{27}$ The first panel of Figure 4 provides the median replacement rate (the return measure) by the $5^{\text {th }}$ percentile replacement rate (the risk measure) for the 11 portfolios for each investment strategy separately, while the second panel merges them together. Figure 5 shows the median and $5^{\text {th }}$ percentile replacement rate by investment portfolio and strategy.

As can be seen in the second panel of Figure 4, portfolio 3 with $70 \%$ of assets in bonds and 20 percent in equities, dominates portfolios 1 and 2 that have a lower share of equities, in both the fixed portfolio and the life cycle investment strategies. Portfolio 3 in those two investment strategies provides a higher median replacement rate with a higher replacement rate at the $5^{\text {th }}$ percentile (i.e. replacement rates are above that rate in $95 \%$ of the cases). All 11 portfolios are one-period mean-variance efficient, but over the long-term this is not the case any longer as portfolio 3 dominates the first two under two

\footnotetext{
${ }^{25}$ Each cohort is composed of the people retiring in one particular year.

${ }^{26}$ The annex provides the figures with the mean and standard deviation for those interested.

${ }^{27}$ The annex provides median replacement rates by level of risk and the $5^{\text {th }}$ percentile for each of the investment policies for people contributing and accumulating assets in a DC pension plan during 20 years.
} 
investment strategies. The replacement rate is the result of accumulating returns over a long period, which stresses the importance of focusing on the geometric mean instead of the arithmetic mean when examining the impact of investment policies on retirement income.

The choice among the other 29 investment policies depends on the balance between risk and the expected replacement rate people wants to achieve, which in turn depends on their risk aversion. As equity allocation increases by moving from one portfolio to the next, there is a gradually smaller increase in median replacement rates and a gradually larger increase in the risk of unfavourable outcomes (the $5^{\text {th }}$ percentile). This is most visible for the last two portfolios (10 and 11). The life cycle investment strategy provides the highest replacement rate floor at the $5^{\text {th }}$ percentile for all portfolios (figure 4), but it also provides the lowest potential replacement rate at the $95^{\text {th }}$ percentile. The dynamic risk budget, on the other hand provides the highest potential median replacement rate and the highest replacement rate at the $95^{\text {th }}$ percentile, but with a higher downside of risk.

If one considers the choice of portfolio and investment strategy as two separate decisions, however, the dynamic risk budget strategy dominates the other two. Under a dynamic risk budget strategy it is possible to find a portfolio - or a combination thereof - that strictly dominates the other two strategies, in the sense that its reaches a higher median replacement rate for a given level of risk (or a lower level of risk for the same replacement rate). However, this result depends on the risk measure used. If one uses instead the standard deviation, the dynamic risk budget strategy no longer dominates at low to medium risk levels (see Annex, Figure A1). Figure 4 also shows that the life cycle strategy has similar statistical properties as a fixed portfolio strategy with a lower equity allocation than the initial one of the life cycle strategy.

Figure 4. Replacement rate by level of risk and investment policy Individual in DC pension plan for 40 years
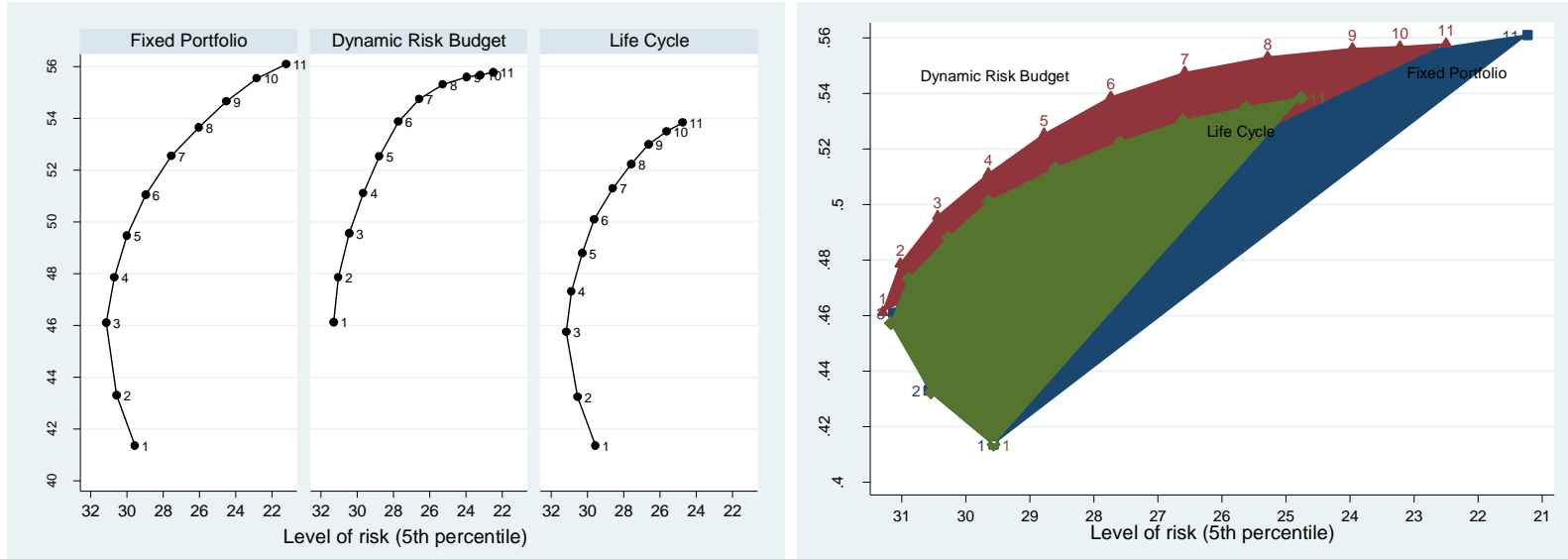

Source: Own calculations 
Figure 5. Median and $5^{\text {th }}$ percentile replacement rates

Individual in a DC pension plan for 40 years
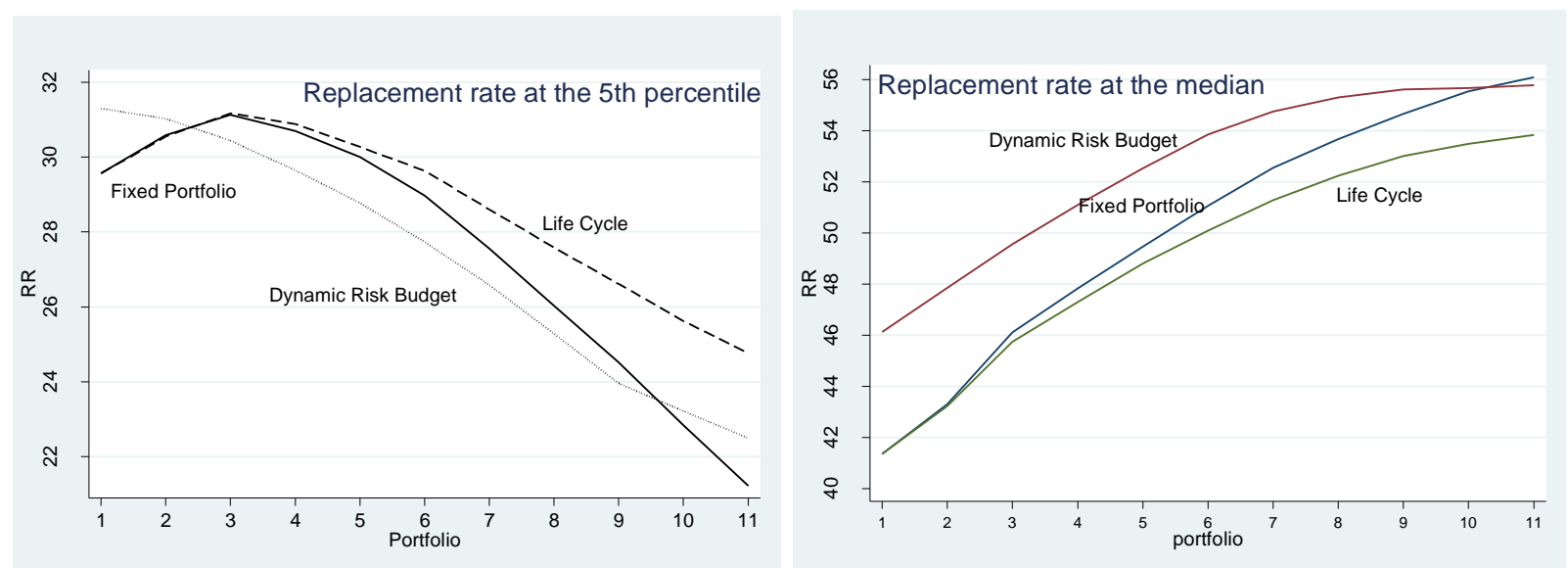

Source: Own calculations

Policy makers establish regulations on investment risk in order to strike this balance between risk and high replacement rates. However, these regulations on investment risks by reducing the type of investment policies available can reduce choice for achieving higher replacement rates at a reasonable increase in the downside risk. The results presented so far show that life-styling may not be the optimal investment strategy for an individual contributing regularly to a DC plan and intends (or is required to) purchase an annuity at retirement. Default options may therefore also consider alternatives such as dynamic risk budgeting which may lead to higher replacement rate outcomes at given risk levels. As reviewed in Section II, policymakers may also apply other quantitative investment regulations which may be more effective in achieving the desired goal of retirement income predictability than simply regulating investment choice and defaults. The next section addresses the impact of these regulations on replacement rates.

\section{The impact of the different regulatory approaches on investment policies available and on the retirement income from $\mathrm{DC}$ pension plans}

This section examines how different regulatory frameworks designed to reduce investment risk affect the replacement rates that retirees in DC pension plans could achieve. In particular, it assesses which of the 33 investment policies - given by 3 investment strategies and 11 initial portfolio allocations -- fulfil the requirements established on investment risk by each of the different regulatory frameworks considered.

The analysis considers the impact of 4 different regulatory frameworks: quantitative investment restrictions, minimum return (and minimum replacement rate) restrictions, the short-term investment restrictions or VaR, and a fourth one based on the replacement rate expected shortfall. The first three are currently used by regulators in several countries, while the fourth one focuses on restricting the worst outcomes around a minimum replacement rate.

\section{Quantitative investment limits on equity allocations}

This regulatory framework establishes that there is a maximum limit on the share of assets invested in equities. As a result of this quantitative limit on equities only some of the initial portfolios remain available. In particular, assuming a ceiling of 30\% in equities, only portfolios 1 to 4 under the fixed portfolio and life cycle strategies, and portfolios 1 and 2 in the dynamic risk budget strategy fulfil this requirement. 
Quantitative limits on equities steer pension funds and people to investment policies with a large share in bonds, reducing the downside risk (given by the $5^{\text {th }}$ percentile) and the volatility (given by the standard deviation). However, it also reduces the potential gains in replacement rates that could result from less conservative investment policies. There is again a balance to strike between risk aversion and potential gains in replacement rate at the expense of higher risks.

Setting quantitative limits on equities can be efficient when those limits are such that the investment policies available are those that dominate in terms of trade-off between replacement rates and risk. For example, setting the limit on equities to $20 \%$ would remove investment policies corresponding to portfolios 3 and 4 under fixed portfolio and life cycle investment strategies, which dominate portfolios 1 and 2 in terms of the trade-off between replacement rate and volatility. Additionally, regulators can only set limits on investments that are efficient a priori but not a posteriori. It depends on whether the model simulations are validated by future events.

\section{Minimum returns}

This regulatory framework establishes that only investment policies that provide a certain minimum return on investments on average over the whole investment horizon with a certain probability are accepted. The analysis looks into two minimum returns, a nominal annual return of $2 \%$ (equal to the average annual rate of inflation) and a nominal annual return equal to the growth of wages $(3.785 \%){ }^{28}$ The later may be useful when comparing with public pensions as the implicit return in public pensions is the growth rate of wages.

These minimum returns are translated into the relevant policy variable, that is, the replacement rate. Therefore, using the same assumptions described in the previous sections about wages, contribution, contribution periods and life expectancy, a minimum rate of return of $2 \%$ translates into a minimum replacement rate of $22 \%$ for people contributing for 40 years given an annuity factor of 13.3 (considering future stochastic developments in life expectancy). For people contributing to a DC plan for 20 years the minimum average annual return of $2 \%$ translates into a $13 \%$ replacement rate. The corresponding replacement rates for a minimum return equal to wage growth are $31 \%$ and $16 \%$, respectively.

The probability threshold to determine which investment policies are allowed depends on the specific circumstances of each country. Countries where DC pension plans are mandatory or they are the main source of retirement income for the average worker, regulators may be inclined to allow only investment policies that provide a replacement rate with a $95 \%$ or even $99.5 \%$ probability that it is higher than the replacement rate resulting from the minimum return. In countries where DC pensions are voluntary and complementary to public pensions, regulators may be less strict and allow investment policies that provide a higher replacement rate with a probability equal to $80-85 \%$. Such regulations may be interpreted as a rate of return target or objective rather than a hard guarantee. ${ }^{29}$

An average annual nominal minimum return of $2 \%$ is fulfilled with a probability higher than $95 \%$ by almost all investment policies when the contribution period is large enough. For shorter contribution periods (e.g. 20 years) investment policies with more than $70 \%$ in equities fail to provide a replacement rate higher than the minimum with a $95 \%$ probability.

Increasing the probability requirement (e.g. investment policies providing a replacement rate higher than the minimum $99.5 \%$ of the time) reduces the investment policies available to those where

\footnotetext{
${ }^{28}$ In other words, the minimum annual return in real terms is equal to productivity growth

${ }^{29}$ Hard guarantees, whether offered by pension funds or insurance companies, are usually subject to solvency regulations. Risk-based regulations require these institutions to have funding levels sufficient to meet the guarantee with a high level of certainty (e.g. $97.5 \%$ in the Netherlands for pension funds or $99.5 \%$ under Solvency II for insurers)
} 
the share of bonds is over $50 \%$ for contribution periods of 40 years, and over $65 \%$ for contribution periods of 20 years.

More strict minimum return regulations (e.g. an average annual nominal minimum return equal to wage growth), render all investment policies unavailable when the level of security or confidence level is set at the 95\% likelihood or higher. More lenient security requirements (lower probability of reaching the minimum) are fulfilled only by those investment policies with a large allocation in bonds.

Regulatory frameworks focusing on minimum replacement rates instead of minimum returns would produce the same type of results, as minimum returns translate into replacement rates and vice versa. The share of bonds in the investment policies fulfilling a minimum replacement rate criteria increases directly with that minimum return and the security level required, and decreases with the length of the contribution period.

Figure 6. Minimum average annual nominal return of $2 \%$
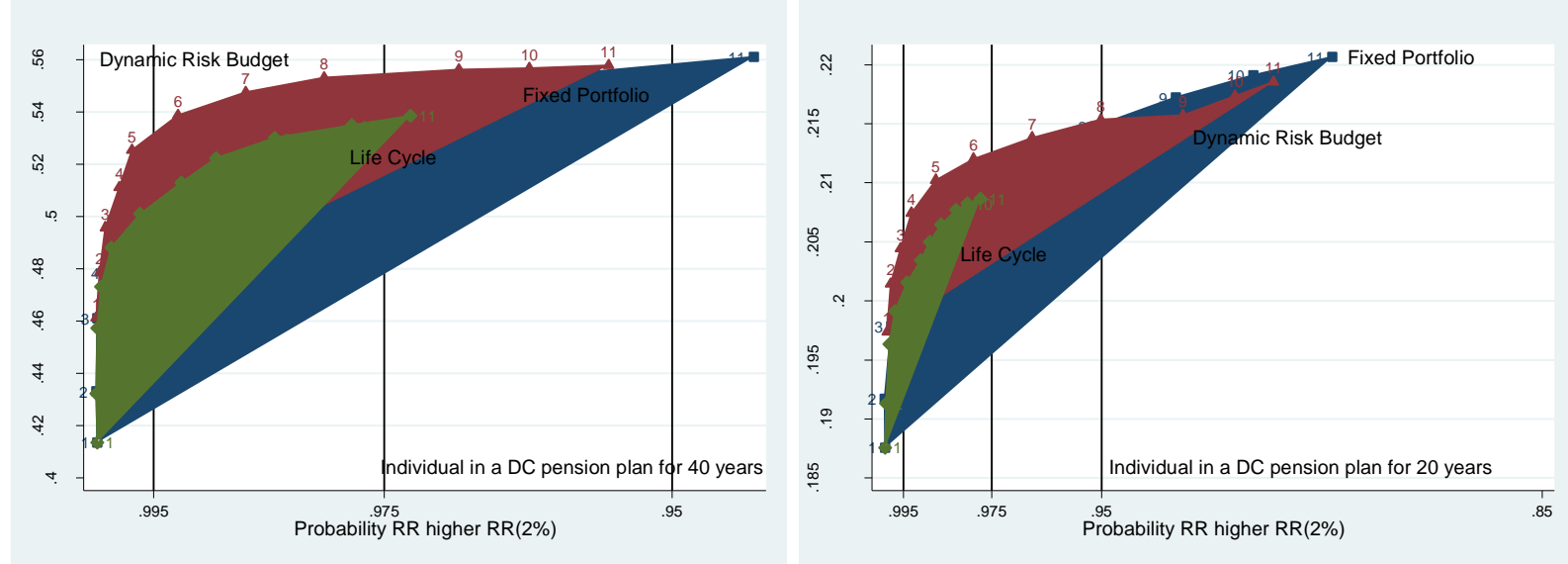

Source: Own calculations

Figure 7. Minimum average annual nominal return of $3.785 \%$
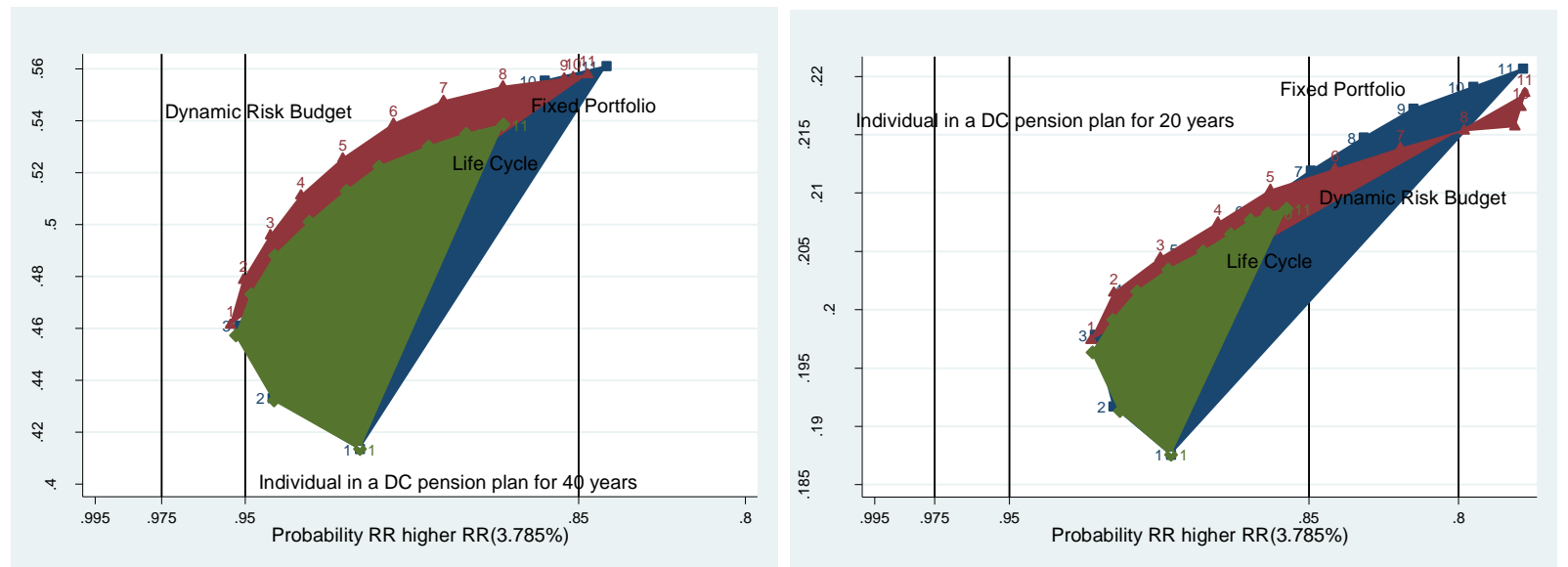

Source: Own calculations

\section{Short-term investment return or VaR}

The VaR regulatory framework modelled establishes that investment policies with a monthly portfolio return below $-2 \%$ in more than $5 \%$ of the cases are removed. In other words, only investment 
policies with short-term returns above $-2 \%$ in 95 percent of the cases are available. ${ }^{30}$ Applying this short-term investment return regulation steers pension funds and investor to investment policies with a share in equities of $30 \%$ or less. It can be argued that this is a complicated way of achieving similar results as under the previous regulatory frameworks.

An important difference is that the investment policies available under this regulatory framework are independent of the length of the contribution and accumulation period. They just depend on the regulation requirements, while in the other regulatory approaches is the combination of the regulation requirements and the accumulation period that determines the type of investment policies available. Another difference between a VaR regulation and quantitative investment restrictions is that the VaR can capture the aggregate portfolio risk from a variety of asset classes and derivative products. The model used simplifies the portfolio choice problem to four main asset classes, turning equity ceilings into a relatively straightforward tool to limit aggregate portfolio risk.

Figure 8. VaR

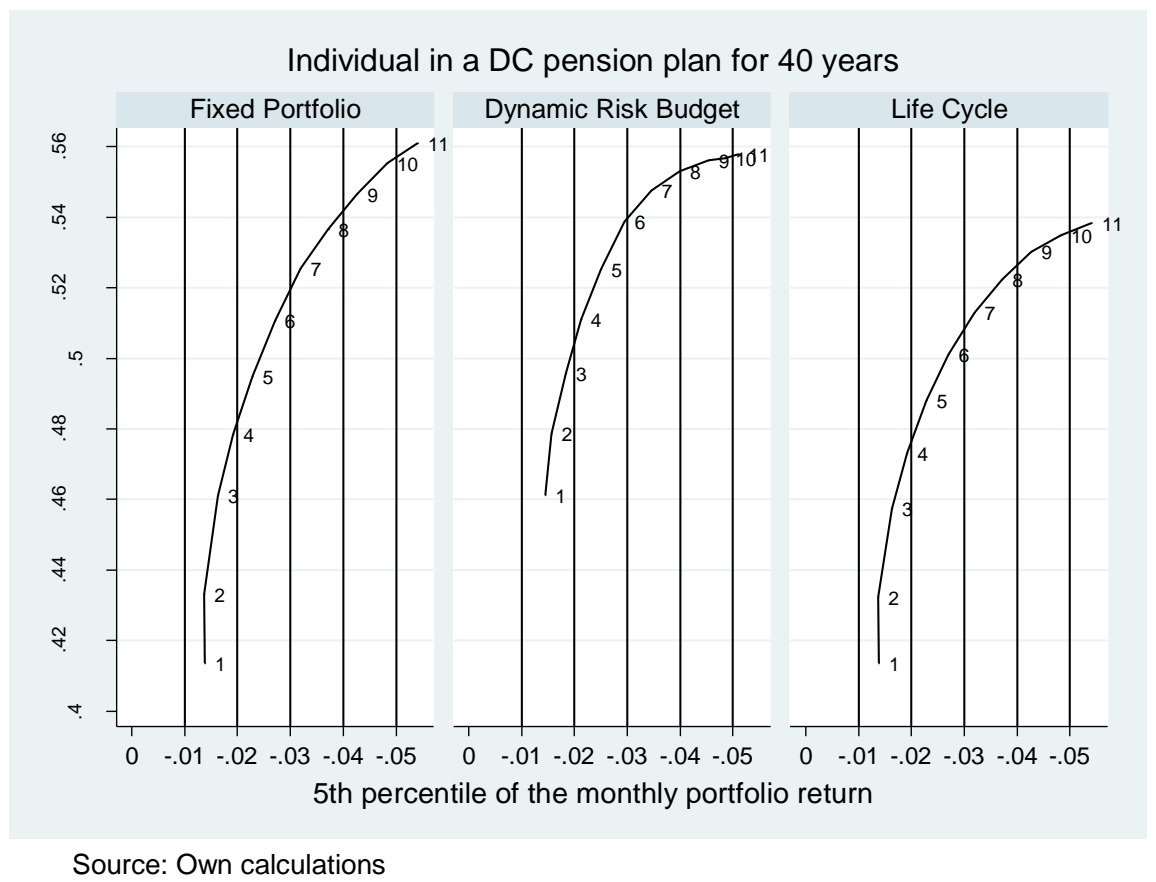

\section{Replacement rate expected shortfall}

The regulatory framework based on a replacement rate expected shortfall modelled establishes that only investment policies where replacement rates below the minimum replacement rate are within the shortfall bracket in $95 \%$ of the cases are considered. For example, setting a expected shortfall of 5 percentage points and a minimum replacement rate of $25 \%$, only investment policies in which the distribution of replacement rate is such that $95 \%$ of the cases where the replacement rate is below $25 \%$, those replacement rates are within the bracket of $20-25 \%$ replacement rates. ${ }^{31}$

\footnotetext{
${ }^{30}$ Regulations based on short-term investment returns may lead to inefficient, pro-cyclical feedback investment strategies among pension funds, i.e. forcing equity sales when the prices go down, reducing further returns, and forcing further equity sales. The model used here abstracts from this effect as investment strategies are fixed for the whole accumulation period.

${ }^{31}$ This is equivalent to checking the concentration on the left tail of the minimum replacement rate given by the allowed shortfall rate.
} 
This regulatory framework combines the requirement of a minimum replacement rate with requiring that those cases in which the replacement rate falls below the minimum are concentrated close to the minimum. That is, it requires that the worst case scenarios below the minimum are not far below the minimum with a certain probability.

The main results of subjecting the 33 investment strategies to this regulatory framework are reported in figures 9 and 10, for a minimum replacement rate of $25 \%$ and $15 \%$ respectively. These figures provide the probabilities that the replacement rates falling below the minimum replacement rates are within the 5 percentage point shortfall interval (i.e. within [20\%-25\%] or [10\%-15\%]).

The length of the contribution and accumulation period determines whether a minimum replacement rate is too demanding. For example, for a period of 20 years a minimum replacement rate of $25 \%$ given the contribution rate of $10 \%$ assumed in the model is too demanding as it renders all investment policies unavailable. Only a minimum replacement rate of say $15 \%$ begins to render a few investment policies available. The share of assets invested in bonds would then depend on whether the regulation set the probability of falling within the shortfall interval at $80 \%$ (e.g. the case of a country where DC plans are voluntary and complementary to a public pension) or at $99.5 \%$ (e.g. the case of a country where DC plans are mandatory and the main source of retirement income).

For long enough contribution periods (e.g. 40 years) replacement rates are above the 15\% minimum replacement rate with $100 \%$ probability in all investment policies with $50 \%$ or more in bonds. Moreover, in the other investment policies almost all fall within the shortfall interval with a $95 \%$ probability. Under the more demanding minimum replacement rate of $25 \%$, investment policies with $50 \%$ or more in bonds fall within the shortfall interval with an $80-85 \%$ probability. Increasing the probability requirement to $99.5 \%$ renders unavailable all investment policies but those with more than $70 \%$ in bonds.

Figure 9. Replacement rate expected shortfall of 5 percentage points below a $25 \%$ minimum replacement rate
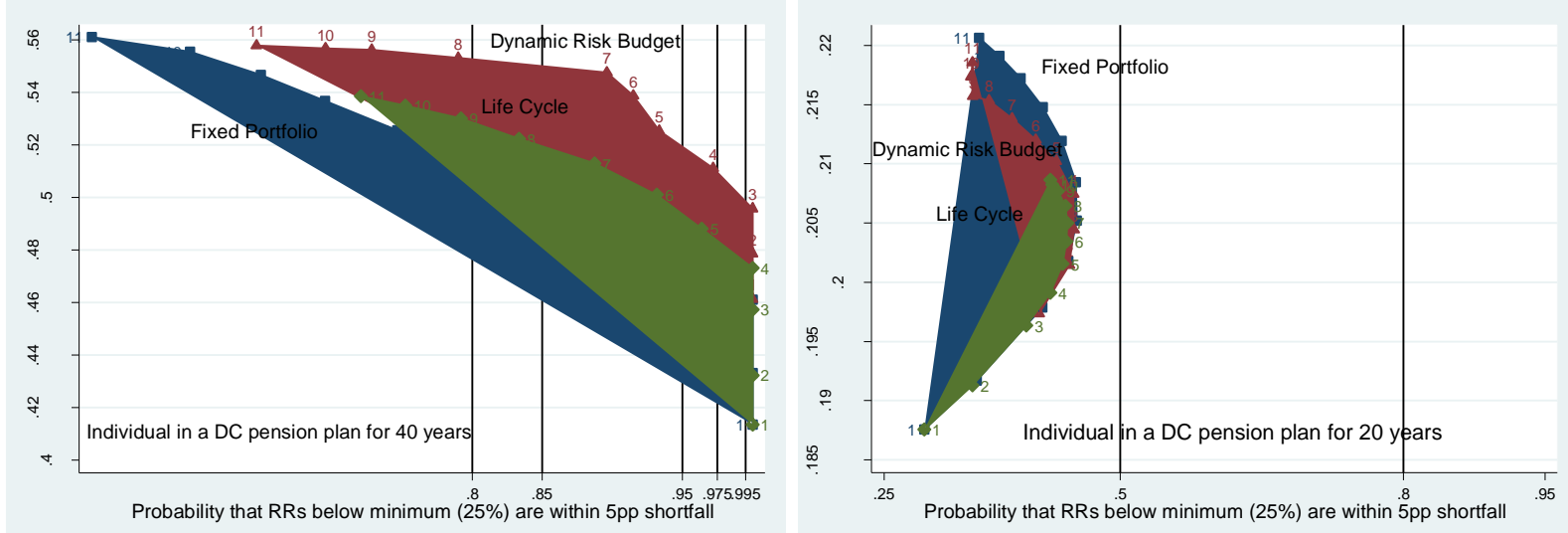

Source: Own calculations 
Figure 10. Replacement rate expected shortfall of 5 percentage points below a $15 \%$ minimum replacement rate
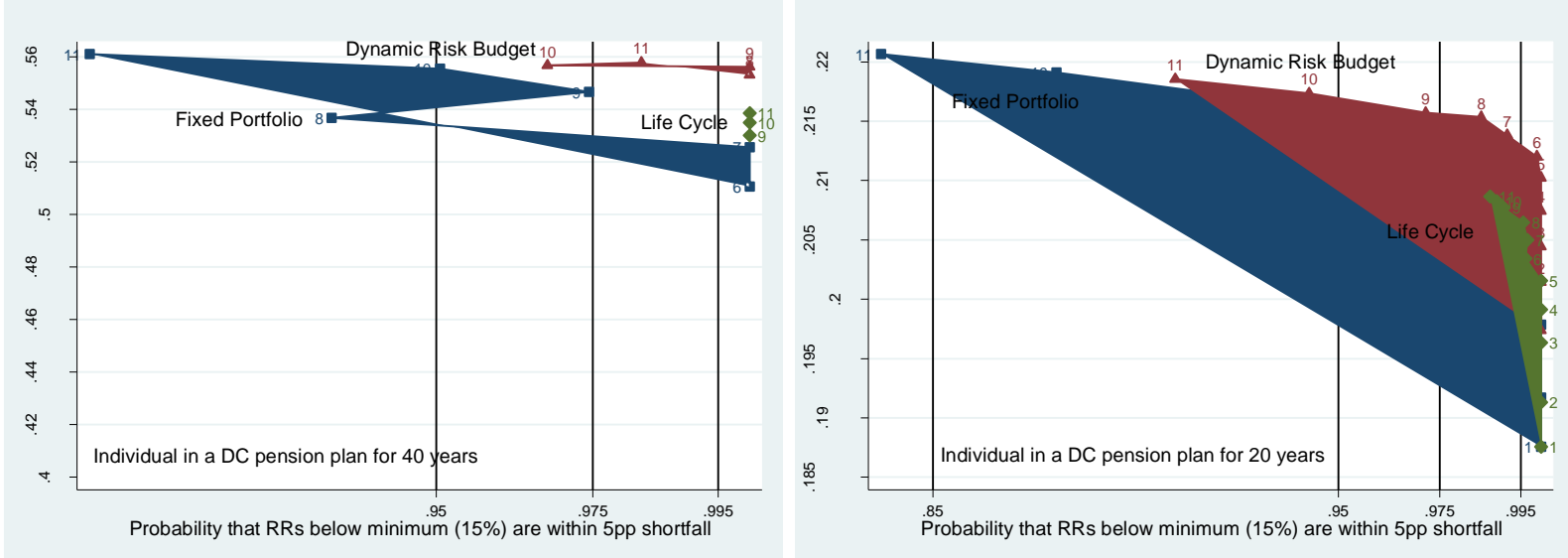

Source: Own calculations

\section{Sensitivity analysis for different equity premiums}

The sensitivity analysis shows that the results discussed so far are reasonably robust to different assumptions regarding equity premiums. These results are founded on certain assumptions as regard equity and fixed income returns. In particular, the equity premium assumed is equal to 2 percentage points (table 3). ${ }^{32}$ Figure 11 reports the median replacement rate given the level of risk for each investment policy for an equity premium of 3 percentage points. The results are broadly similar to those in Figures 4 and 5.

Consequently, changing the equity premium does not alter the main thrust of the model. Reducing the downside risk requires moving into more conservative investment policies, but at the cost of renouncing potential higher replacement rates. However, increasing the equity premium raises the equity allocation of the portfolio that provides the highest replacement rate at the lowest level of risk. Moreover, as the equity premium increases, the life cycle investment strategy becomes less dominant when focusing on the worst case scenario (replacement rates at the $5^{\text {th }}$ percentile).

Figure 11. Replacement rate by level of risk and investment policy and at the $5^{\text {th }}$ percentile Individual in DC pension plan for 40 years
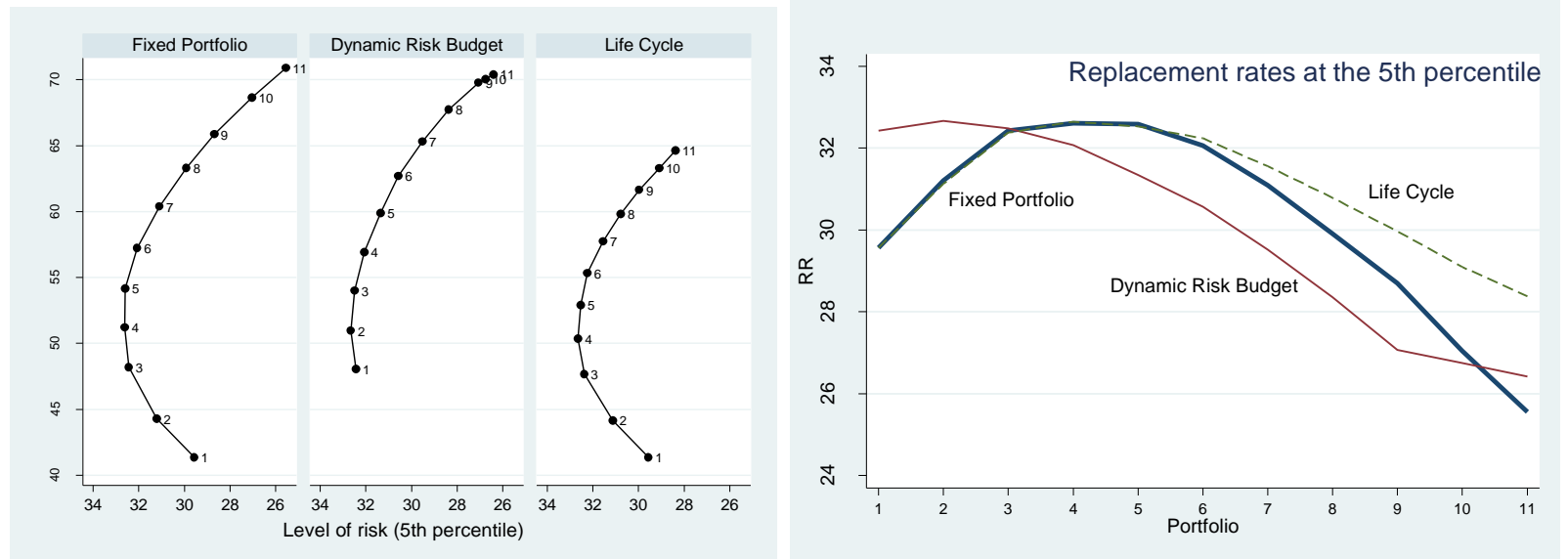

Source: Own calculations assuming an equity premium of 3 percentage points, which it is one percentage points higher than in the previous figures.

\footnotetext{
${ }^{32}$ Credit Suisse Global Investment Returns Yearbook 2009 reports that the United States equity premium with respect to bills has been 5 and 3.8 percentage points in the last 108 and 50 years, respectively. The corresponding numbers for Germany are 3.4 and 3.2 percentage points.
} 


\section{Conclusions and implications for policy}

Individual accounts or DC pension plans are growing in importance throughout the world and are even becoming part of mandatory retirement income systems. Despite their many advantages, DC systems subject retirement benefits to a great deal of uncertainty. Regulations can be designed so as to limit some of these risks and avoid situations where older workers and retirees are exposed to major losses on their retirement income. This section discusses the main regulatory approaches that seek to minimise the risk of unfavourable retirement income outcomes through quantitative investment regulations on equity investment. As well as summarising the main conclusions of the analysis, it presents several policy implications and considerations to inform public policy debate on the trade-off to strike between retirement income outcomes and risk.

\section{$>\quad$ The regulation of investment choice and default options in mandatory DC plans should be carefully designed}

The results presented show that regulations of investment choices and default options need more careful implementation than has been the case up to the present. Some countries with mandatory DC systems are still not allowing investment options to individuals. They only provide a single portfolio for all participants irrespective of age or other factors such as size of the DC portion or the choice of payout.

The weight of the DC portion in total retirement income appears to be a key deciding factor in the current design of defaults. For example, in Sweden, where the mandatory DC system accounts for a small part of the total mandatory pension, the default fund is largely invested in equities (around 90\%). While the amount invested is small, it may be appropriate to reduce the risk as the individual approaches retirement. In Chile and Mexico, where the mandatory DC pension is very large in relation to total income, the default fund for a worker ten years from retirement has a maximum $20 \%$ and $0 \%$ allocation to equities, for each country respectively.

In contrast, some European countries with mandatory DC systems like Estonia, Hungary and the Slovak Republic have set the conservative portfolio (with no equities) as the default for all ages. Such portfolios may be inadequate for younger cohorts as they imply lower expected retirement benefits.

Finally, in Australia, the default option for the mandatory DC pension system - which provides a large part of retirement income - is not regulated, and is often in practice a balanced fund with a large equity allocation (over $60 \%$ in some cases). Such defaults can only be reconciled with individuals that may be less risk adverse than the average and do not wish to transform their balances into annuities and have predictable incomes after retirement. A sharp drop in returns, such as the one taking place in 2008, can expose older people to an irremediable decline in living standards.

\section{$>\quad$ In a retirement context, the risk-return trade-off of different investment portfolios and strategies should be evaluated by looking at projected retirement benefits}

The traditional approach to assessing investment strategies is to focus on short-term investment return and risk. In a retirement context, however, the objective is to maximise retirement benefits subject to a given risk level. Stochastic models can be used to make retirement benefit projections from which relevant statistical measures can be calculated. The analysis of this paper uses the replacement rate at the $5^{\text {th }}$ percentile and the median replacement rate to map the risk-return trade-off of different investment portfolios (distinguished by their allocation to four main asset classes - cash, bonds, equities and real estate) and investment strategies (fixed portfolio, life-cycle and dynamic risk budget) given a fixed contribution rate and full conversion of the accumulated savings at retirement into a lifetime annuity. 
The analysis corroborates earlier findings showing that an investment portfolio may be meanvariance efficient in the short-term but inefficient when looked at through the lens of a pension plan member. For some investment strategies both very low allocations to equities (below 20\%) and very high ones (above 80\%) look unattractive in terms of the trade-off between replacement rate expectations and risk. In between, however, there is a wide range of options for plan members and regulators to consider.

\section{$>\quad$ Alternatives to conventional life-cycle investment strategies should be evaluated, especially when used as default options}

More careful analysis is also needed on the design of suitable life-cycle investment strategies, especially when used as default options/ The modelling results show that a naïve life-cycle investment strategy - reducing equity investment to zero over the last ten years before retirement - may not be the optimal investment strategy for an individual contributing regularly to a DC plan and intending to purchase an annuity at retirement. As long as there are no portfolio restrictions, a dynamic risk budgeting strategy may achieve a higher replacement rate outcome for the same risk level. However, this result depends on the risk measure used. If one uses instead the standard deviation, the dynamic risk budget strategy no longer dominates at low to medium risk levels.

The life cycle strategy modelled also has similar statistical properties as a fixed portfolio strategy with a lower equity allocation than the initial one of the life cycle strategy. While life cycle strategies do indeed reduce retirement income risk they do so at the cost of lower pensions on average.

\section{Various quantitative regulations can be established to limit retirement income risk in DC systems}

The analysis also confirms that quantitative investment regulations can be used to restrict investment policies to those that provide a certain combination of potential retirement income and risks. Risk adverse regulators and supervisors - as may exist in those countries where DC plans provide a large portion of retirement income - will aim at policies that reduce the downside risk or that minimise the risk of unfavourable outcomes from DC plans.

Given reasonable assumptions about risk-return tradeoffs of different asset classes, quantitative regulations such as absolute minimum or target returns (to be achieved with a high level of security, rather than guaranteed), an investment VaR limit, and a maximum replacement rate expected shortfall when applied with a security level higher than $95 \%$ - would all require moving into relatively conservative investment policies, where the share of assets allocated in bonds is quite large, generally above $60 \%$. Hence, these risk-based regulations are broadly equivalent to setting a ceiling on investments in equities and other risky assets. Such regulations come at the cost of renouncing potentially higher replacement rates that are attainable but at a higher risk of unfavourable retirement income outcomes. Less risk adverse regulators and supervisors, on the other hand, would aim at lower probability requirements as regard the downside risk (e.g. a security level of $80 \%$ instead of 95\%), which will increase the range of investment policies available and thus the share of riskier assets.

\section{$>\quad$ Simple quantitative regulations such as a ceiling on risky asset classes have some advantages over risk-based regulations}

Policymakers must also consider that regulations could be efficient $a$ priori but inefficient $a$ posteriori depending on whether real events fail to validate the modelling. They must also assess the complexity and cost of implementing and monitoring these different risk measures. Simple regulations (e.g. a quantitative limit on equities of 30-40\%) could achieve the same results than more complicated regulatory approaches (e.g. minimum returns with a certain security level, a VaR ceiling and a maximum replacement rate expected shortfall), but only in the case that the model is validated by real events. 
Moreover, some of these more challenging risk-based regulations can also lead to inefficient, procyclical investment strategies, forcing pension funds to sell equity holdings at times of negative returns. This may be especially the case when the restrictions are applied over short periods, rather than over the whole period of accumulation. Such effects not only damage pension fund performance but are also detrimental to financial stability, of which pension funds are a major pillar. Risk-based regulations are also open to the criticism that they are exposed to modelling discretion and possibly substantial modelling error, as the underlying parameters of the model may not capture the reality of financial markets, as has been the case for bank and insurance risk management models during the 2007-8 financial crisis. The limitations of sophisticated risk modelling have been magnified amidst rapid changes in market conditions.

\section{$>\quad$ The regulatory approach should vary depending on the length of the contribution period and the type of benefit pay-out allowed}

The impact of regulations minimising the risk of unfavourable retirement income outcomes through restrictions on investment risk depends on the length of the contribution and accumulation period. Long periods render possible investment policies with a larger share of riskier assets, increasing the potential for high replacement rates, but also risks. Short contribution periods combined with risk adverse regulators would steer people and pension funds to conservative investment policies when the goal is to reach a reasonable replacement rate with a reasonable downside risk.

The analysis has also focused on DC plans where benefits are converted into lifetime annuities at retirement. If individuals are able and willing to maintain some market exposure after retirement, the suitability of the investment portfolios and strategies modelled would change. Equally, investment regulations can be more flexible, as plan members can wait till markets recover before transforming their accumulated savings into an annuity.

\section{$>\quad$ The design of DC investment regulations should also take into account various country- specific factors}

These results are useful in informing public policy decision regarding the risk-retirement income level trade-off. In this context, it is important to stress that there is not a single correct trade-off. This trade off depends on the country context and on risk aversion levels. In countries where payments from DC pension plans are the main source of retirement income, the cost to the society of downside risks or unfavourable outcomes are much larger than in countries where they have other sources of retirement income, such as public pension provision and defined benefit pension plans.

Other factors such as incentives to achieve desired participation levels, cultural attitudes to financial risks and the nature of the pension promise also affect this trade-off between risk and retirement income. When participation in DC pension plan is mandatory concerns about risk outweigh concerns about potential high replacement rates. For countries where participation is voluntary and people can effectively choose between spending now or saving for retirement, there may be little use in providing a low risk product if the potential for upward gains in retirement income are not attractive relative to the time preference of money. In the same vein, societies more comfortable with the idea that investment in pension plans involves risks and investing in equities, would tolerate greater volatility in retirement income outcomes. Additionally, the nature of the pension promise affects the attitude to investment risk. Framing DC pension plan as "providing security in old age" instead of as "sources of extra money to complement retirement" would influence the severity of the regulations. As a result of all these factors, one would expect a different risk-retirement income trade-off between say Mexico and Chile on the one side, and Australia, the United Kingdom or the United States on the other. 


\section{REFERENCES}

Antolin, P. and F. Stewart (2009), "Private Pensions and Policy Responses the Financial and Economic Crisis" ", OECD Working Paper Series in Insurance and Private Pensions No. 36 doi: $\underline{10.1787 / 224386871887}$

Antolin, P. (2008), "Policy Options for the Payout Phase", OECD Working Paper Series in Insurance and Private Pensions No. 25 doi: 10.1787/238030285260

Antolin, P. (2007), "Longevity Risk and Private Pensions", OECD Working Paper Series in Insurance and Private Pensions No. 3 doi: 10.1787/261260613084

Ashcroft, J. (2009), "Defined Contribution Arrangements in Anglo-Saxon Countries", OECD Working Paper Series in Insurance and Private Pensions No. 35

Campbell, J. Y. and Viceira, L. (2002), "Strategic Asset Allocation: Portfolio Choice for Long-term Investors", Oxford University Press.

Dhaene, J., Goovaerts, M. J., and Kaas, R. (2003), Economic Capital Allocation Derived from Risk Measures. North American Actuarial Journal, 7(2):44-56.

Homeff, W., R. Maurer, O. S. Mitchell, M. Stamos (2008), “Asset Allocation and Location Over the Life Cycle With Survival-Contingent Payouts”, NBER Working Paper No. 14055.

Korn, K. (1997) Optimal Portfolios: Stochastic Models for Optimal Investment and Risk Management in Continuous Time, World Scientific Publishing Company

Markowitz, H. (1952),"Portfolio Selection”, the Journal of Finance, Vol. 7, No. 1, 77-91. Mar. 1952.

Maurer, R. and B. Somova (2009), Rethinking Retirement Income Strategies: How can We Secure Better Outcomes for Future Retirees, EFAMA, February 2009.

OECD (2009), OECD Private Pension Outlook 2008.

OECD (2005), OECD Guidelines on Pension Fund Asset Management

Sharpe, William F. (1964),"Capital asset prices: A theory of market equilibrium under conditions of risk", Journal of Finance, 19 (3), 425-442.

Tapia, W. and Yermo, J. (2007), "Implications of Behavioural Economics for Mandatory Individual Account Pension Systems", OECD Working Papers on Insurance and Private Pensions, No. 11, July 2007, available at http://www.oecd.org/dataoecd/5/22/39368306.pdf. 


\section{ANNEX}

\section{A. Additional Figures}

\section{Figure A1. Mean replacement rates by level of risk as measured by the standard deviation}
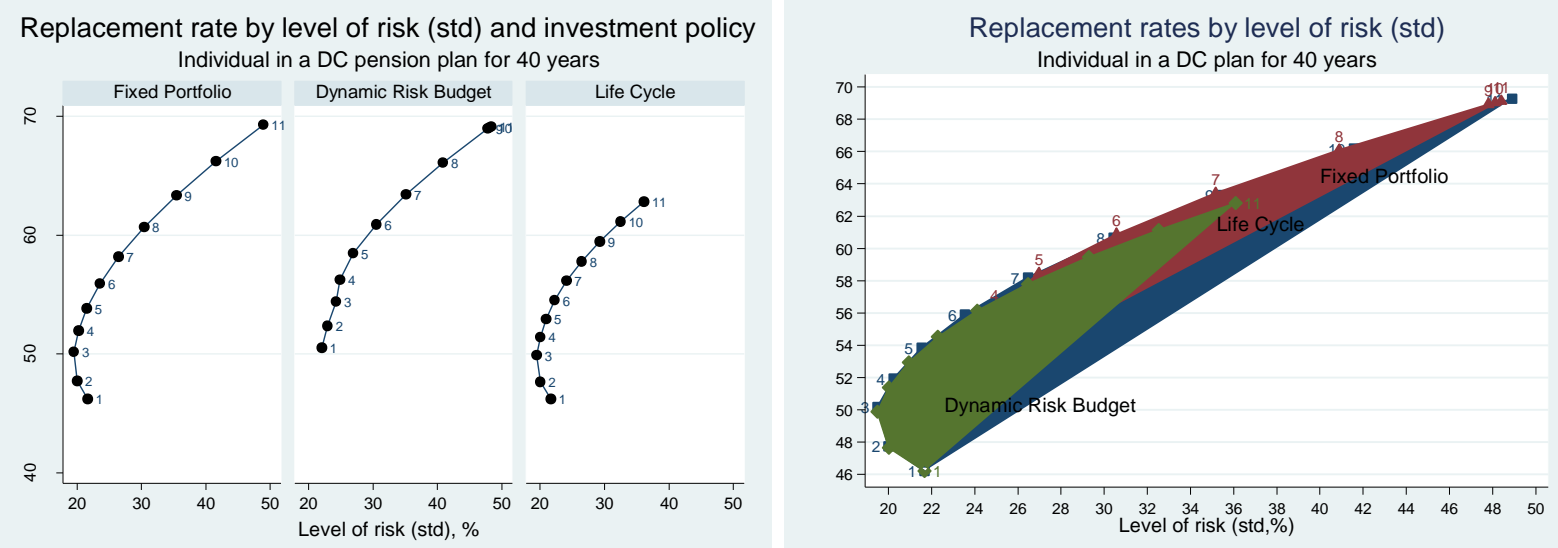

\section{Figure A2. People 20 years in a DC pension plan}
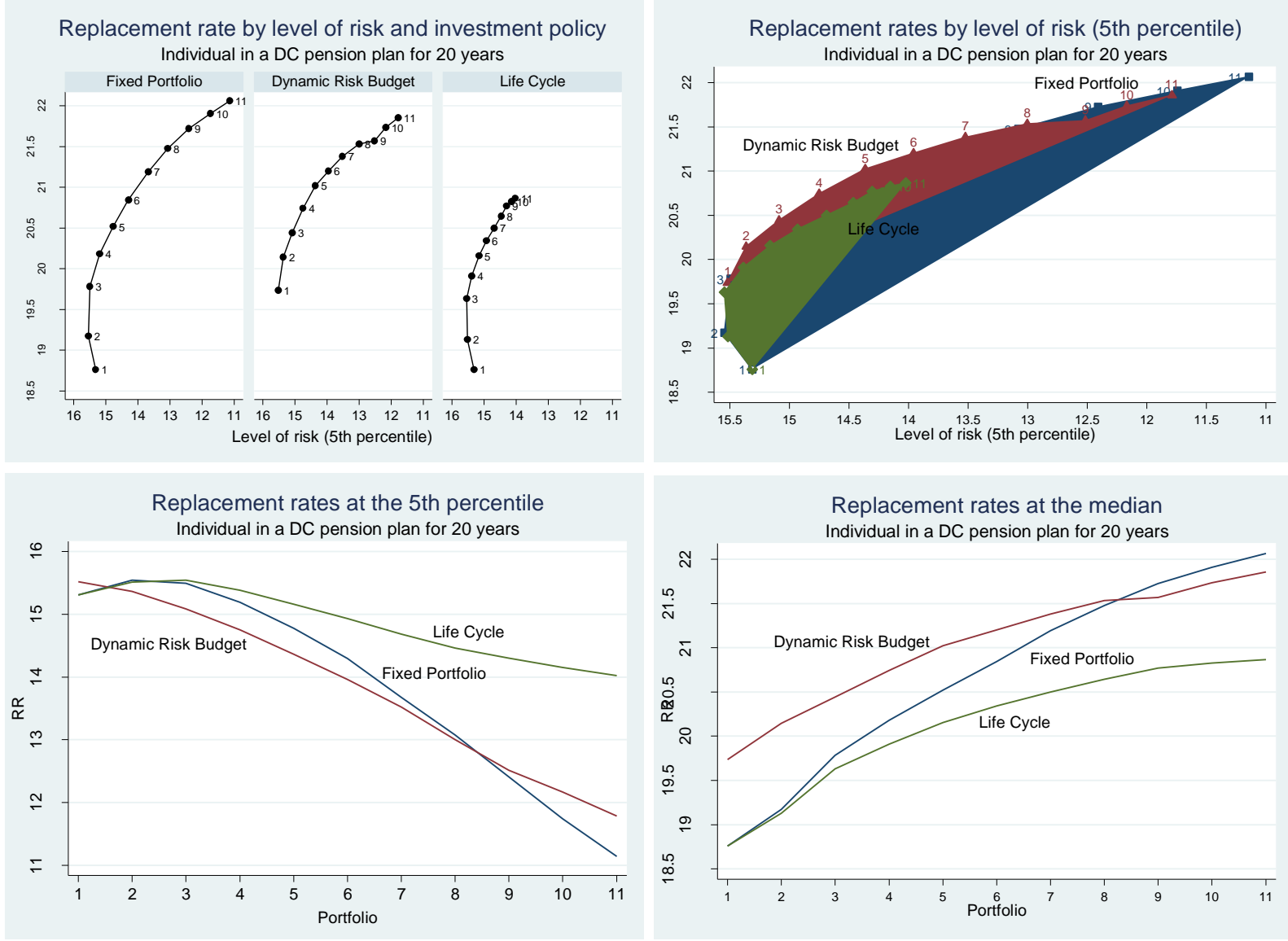


\section{B. Economic Scenario Generator}

Scenario analyses have become a powerful tool to assess complex financial decision situations. With increased computational power, intensive analyses with many economic variables over several time steps have meanwhile become a feasible task.

The quality of the results and conclusions drawn upon depend heavily on the economic scenarios assumed within the analysis. So the underlying concept of the scenario generation is crucial. Different Economic Scenario Generators (ESGs) have been developed and described in the literature ${ }^{33}$. Among the available ESGs, three classes can be distinguished in terms of the underlying model:

- The econometrics-based models.

- The pricing-based models.

- The hybrid models.

The first one is based on statistical and econometric theory ${ }^{34}$. The main advantage of this ESG class is its simplicity, i.e. its transparency as far as the understanding of the market is used, but this also underlines its drawback. A fully historical-based method is not suitable or at least not robust enough for forecasting purposes because it depends on the number of available observations. Besides, this kind of models cannot be used to price financial instruments since simulations under the risk-neutral measure are not possible.

The second class brings a solution for the latter issues. Indeed, these models are based on stochastic mathematical tools which allow risk-neutral calculations. The pricing-based models ${ }^{35}$, unlike the econometrics-based ones, can accommodate for both expressing historical information as well as future expectation. However, risk factors, e.g. inflation or interest rate, may not be in line with global understanding of the market since the focus of these models is put on pricing.

Thus a third class of ESGs evolved. The hybrid model, where risklab's ESG ${ }^{36}$ is one example, tries to combine the main advantages of both previous classes. The logic behind these complex models is to embed our understanding of the market in building the Stochastic Differential Equations (SDEs), in order to capture the link between the main risk factors. Indeed the model, which is implemented in the risklab ESG, aims to overcome the drawback of the pricing-based ESGs by including the influence of macroeconomic variables in the integrated modelling framework. It combines both statistical and financial theory in the sense that it uses observable financial variables like inflation to describe the evolution of other economic variables that are not necessarily observable. To achieve this kind of

\footnotetext{
${ }^{33}$ A.D. Wilkie, M.A., F.F.A., F.I.A. (1995), 'More on a stochastic asset model for actuarial use', British Actuarial Journal. 1, 777-964.

J. Hibbert, P. Mowbray, C. Turnbull (2001), 'A stochastic asset model \& calibration for long-term financial planning purposes'.

R. Zagst, S. Antes, B. Schmid, M. Ilg (2008), 'Empirical evaluation of hybrid defaultable bond pricing models', Journal of Applied Mathematical Finance.

${ }^{34}$ The Wilkie Investment Model, very popular in the United Kingdom, is a prominent representative of these kinds of models. The first version was released in 1986 and the second one in 1995.

35 The Barrie and Hibbert Model is a prominent representative of these kinds of models. Insights have been published in 2001.

${ }^{36}$ The risklab economic scenario generator is a proprietary ESG which is enhanced in cooperation with Prof. Dr. Rudi Zagst, Professor of Mathematical Finance at the Munich University of Technology.
} 
sophistication, the underlying processes are modelled by SDEs with parameters that are estimated gradually following a cascade structure.

Figure B1. Cascade structure used to model the risklab's ESG

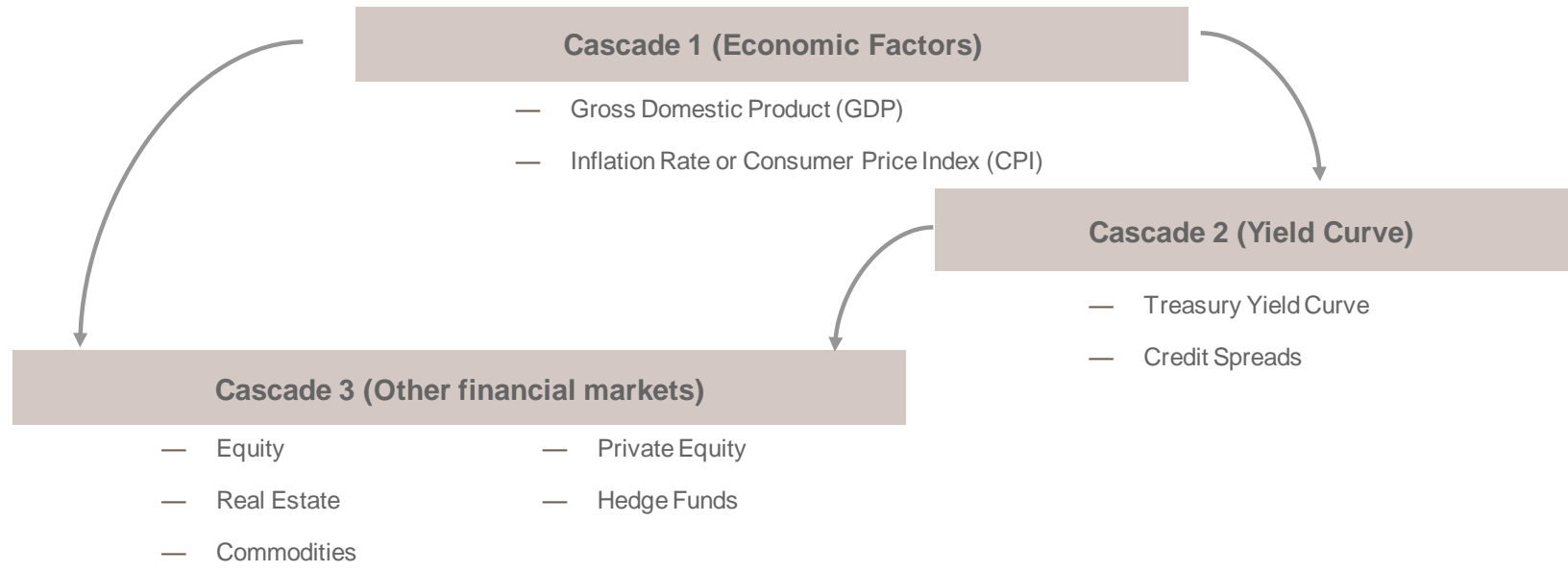

The advantage of such integrated models is to allow the estimation of a complex market model with different interdependent factors step by step. Thus if inflation is a top generating economic factor, then all the factors modelled below it might depend on inflation. All the processes in Cascade 1 and Cascade 2 are modelled with a mean reversion property in mind which means that the processes tend towards their long-term mean, which is economically reasonable and can be observed in the market, especially for interest rates.

Cascade 1 deals with the macroeconomic parameters such as the Gross Domestic Product (GDP) and the inflation. The dynamics of the GDP growth rate $r_{\omega}$ and the dynamics of the inflation rate $r_{i}$ are respectively given by the following Vasicek ${ }^{37}$ model:

$$
\begin{aligned}
& d r_{\omega}(t)=\left(\theta_{\omega}-a_{\omega} r_{\omega}(t)\right) d t+\sigma_{\omega} d W_{\omega}(t) \\
& d r_{i}(t)=\left(\theta_{i}-a_{i} r_{i}(t)\right) d t+\sigma_{i} d W_{i}(t)
\end{aligned}
$$

where $W_{\omega}=\left(W_{\omega}(t)\right)_{t \geq 0}$ and $W_{i}=\left(W_{i}(t)\right)_{t \geq 0}$ are Wiener processes. The mean reversion levels are given by $\frac{\theta_{\omega}}{a_{\omega}}$ for (1) and $\frac{\theta_{i}}{a_{i}}$ for (2).

Cascade 2 deals with the treasury yield curves and the credit spreads. Concerning the treasury yield curve the real short rate $r_{R}$ dynamics is given by a two-factor Hull-White ${ }^{38}$ model.

$$
d r_{R}(t)=\left(\theta_{R}(t)+b_{R \omega} \omega(t)-a_{R} r_{R}(t)\right) d t+\sigma_{R} d W_{R}(t)
$$

\footnotetext{
${ }^{37}$ The Vasicek model describes the evolution of rates and was the first one to capture the mean reversion characteristic. It was introduced in 1977 by Oldrich Vasicek.

${ }^{38}$ The Hull White model was introduced in 1990 by John Hull and Alan White. The Vasicek model is a derived form of the Hull White model.
} 
where $W_{R}=\left(W_{R}(t)\right)_{t \geq 0}$ is a Wiener process. The mean reversion level is given by $\frac{\theta_{R}(t)+b_{R \omega} \omega(t)}{a_{R}}$.

Since the nominal short rate is defined as the sum of the real short rate and the inflation short rate, i.e. $r=r_{R}+r_{i}$, the dynamics of the nominal short rate can be deduced from (2) and (3).

Concerning the short rate credit spread, its dynamics is given by a three-factor Hull-White model, where one driving factor is the so-called uncertainty index $u$.

$$
\begin{aligned}
& d u(t)=\left(\theta_{u}-a_{u} u(t)\right) d t+\sigma_{u} d W_{u}(t) \\
& d s(t)=\left(\theta_{s}+b_{s u} u(t)-b_{s \omega} \omega(t)-a_{s} s(t)\right) d t+\sigma_{s} d W_{s}(t)
\end{aligned}
$$

where $W_{u}=\left(W_{u}(t)\right)_{t \geq 0}$ and $W_{s}=\left(W_{s}(t)\right)_{t \geq 0}$ are Wiener processes. The mean reversion level is given by $\frac{\theta_{s}+b_{s u} u(t)-b_{s \omega} \omega(t)}{a_{s}}$.

Cascade 3 deals with the equity and the alternatives indexes. The dynamics of the stock return $r_{E}$ is given by the following stochastic differential equation:

$$
d r_{E}(t)=\left(\alpha_{E}+b_{E \omega} \omega(t)-b_{E i} i(t)+b_{E R} r_{R}(t)\right) d t+\sigma_{E} d W_{E}(t)
$$

where $W_{E}=\left(W_{E}(t)\right)_{t \geq 0}$ is a Wiener process.

The dividend yield $r_{D}$ dynamics is given by a Vasicek model, which means again that the property of mean reversion is being kept:

$$
d r_{D}(t)=\left(\theta_{D}-a_{D} r_{D}(t)\right) d t+\sigma_{D} d W_{D}(t)
$$

where $W_{D}=\left(W_{D}(t)\right)_{t \geq 0}$ is a Wiener process. The mean reversion level is given by $\frac{\theta_{D}}{a_{D}}$.

\section{Portfolio Set}

In order to profit from diversification effects and to follow a prudent person approach, we use different asset classes, which are as follows:

- Cash (money market).

- Bonds (composed of government and corporate bonds).

- Equity (world stocks).

- Property (Real Estate Investment Trust). 
The theory of Markowitz combined with two restrictions (maximum allocation of 5\% in cash and $10 \%$ in property) leads to the following 11 one-period (month) efficient portfolio allocations used to represent the different DC plans analyzed in this paper.

Figure C1. Set of 11 one-period Markowitz efficient portfolios

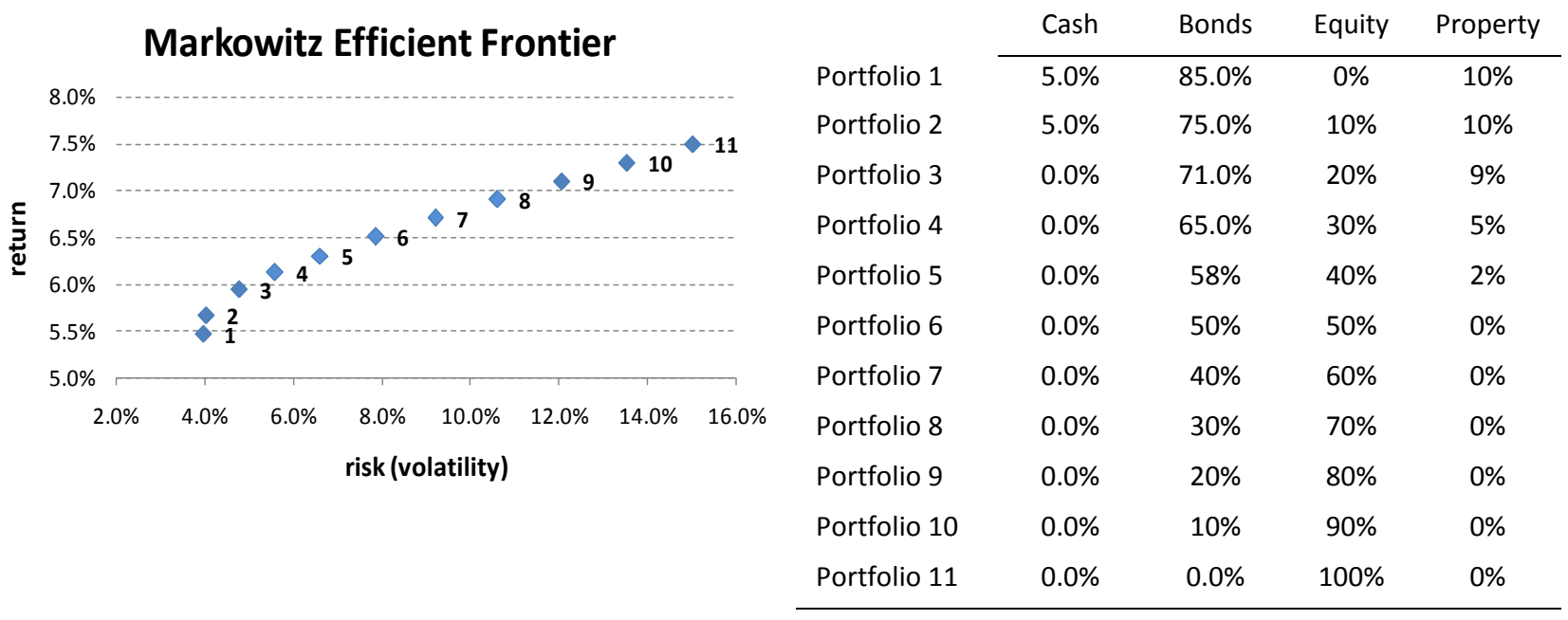

This set of efficient portfolios intends to represent a large investment range met in the DC pension world, from the most conservative to the most aggressive plans which represent to some extend the default plans in many Anglo-Saxon countries.

\section{Investment Strategies}

Three different types of investment strategies (fixed portfolio, life cycle and dynamic risk budget) have been modelled. They are applied to each of the 11 portfolio allocations (see section B Portfolio Set). A combination of a portfolio allocation and an investment strategy is called an investment policy. Thus there are 33 investment policies in total.

The fixed portfolio strategy is a classical strategy that re-adjusts (rebalances) the portfolio asset allocation to the start allocation at the end of each month.

Life cycle strategies are required in the UK for stakeholder pensions and are common for trust based DC plans. In the US, plans for qualified default options use life style elements ${ }^{39}$ as well. The aim of this investment strategy is to reduce the risk of an individual in the last years before retirement. With this perspective the life cycle strategy has been designed to enable a reduction of the portfolio return volatility, as the retirement date approaches, by switching into more defensive portfolio allocations. This strategy intends to replicate the life-styling approach applied in the UK and the US. The more aggressive the portfolio start allocation is the higher the impact of this strategy is. For a given portfolio start allocation $i \in\{1, . ., 11\}$, the assets will be dynamically allocated according to the following rule:

$$
\text { portfolio allocation }=\left\{\begin{array}{cc}
\text { portfolio start allocation } i, & \text { while } i \leq 65-\text { age } \\
65-\text { age }, & \text { otherwise }
\end{array}\right.
$$

For instance, the start allocation of portfolio 8 will be reallocated into the more conservative allocation of portfolio 7 at the age of 58. One year later the allocation of portfolio 7 is reallocated into the even more defensive allocation of portfolio 6 . This process continues until the age of 64 when the

\footnotetext{
${ }^{39}$ Cf. paragraphs 20 and 21.
} 
portfolio is invested in the most defensive allocation. For the start allocation of portfolio 1, there will be no reallocation, which means that the strategy behaves like a rebalancing. The following table summarizes the fade out characteristic that this strategy is involving.

Table D1. Dynamics of the life cycle investment strategy

\begin{tabular}{|c|c|c|c|c|c|c|c|c|c|c|c|}
\hline & $\begin{array}{c}\text { Portfolio } \\
1\end{array}$ & $\begin{array}{c}\text { Portfolio } \\
2\end{array}$ & $\begin{array}{c}\text { Portfolio } \\
3 \\
\end{array}$ & $\begin{array}{c}\text { Portfolio } \\
4\end{array}$ & $\begin{array}{c}\text { Portfolio } \\
5\end{array}$ & $\begin{array}{c}\text { Portfolio } \\
6\end{array}$ & $\begin{array}{c}\text { Portfolio } \\
7\end{array}$ & $\begin{array}{c}\text { Portfolio } \\
8 \\
\end{array}$ & $\begin{array}{c}\text { Portfolio } \\
9\end{array}$ & $\begin{array}{c}\text { Portfolio } \\
10 \\
\end{array}$ & $\begin{array}{c}\text { Portfolio } \\
11\end{array}$ \\
\hline Age & Alloc. & Alloc. & Alloc. & Alloc. & Alloc. & Alloc. & Alloc. & Alloc. & Alloc. & Alloc. & Alloc. \\
\hline 50 & 1 & 2 & 3 & 4 & 5 & 6 & 7 & 8 & 9 & 10 & 11 \\
\hline 51 & 1 & 2 & 3 & 4 & 5 & 6 & 7 & 8 & 9 & 10 & 11 \\
\hline 52 & 1 & 2 & 3 & 4 & 5 & 6 & 7 & 8 & 9 & 10 & 11 \\
\hline 53 & 1 & 2 & 3 & 4 & 5 & 6 & 7 & 8 & 9 & 10 & 11 \\
\hline 54 & 1 & 2 & 3 & 4 & 5 & 6 & 7 & 8 & 9 & 10 & 11 \\
\hline 55 & 1 & 2 & 3 & 4 & 5 & 6 & 7 & 8 & 9 & 10 & 10 \\
\hline 56 & 1 & 2 & 3 & 4 & 5 & 6 & 7 & 8 & 9 & 9 & 9 \\
\hline 57 & 1 & 2 & 3 & 4 & 5 & 6 & 7 & 8 & 8 & 8 & 8 \\
\hline 58 & 1 & 2 & 3 & 4 & 5 & 6 & 7 & 7 & 7 & 7 & 7 \\
\hline 59 & 1 & 2 & 3 & 4 & 5 & 6 & 6 & 6 & 6 & 6 & 6 \\
\hline 60 & 1 & 2 & 3 & 4 & 5 & 5 & 5 & 5 & 5 & 5 & 5 \\
\hline 61 & 1 & 2 & 3 & 4 & 4 & 4 & 4 & 4 & 4 & 4 & 4 \\
\hline 62 & 1 & 2 & 3 & 3 & 3 & 3 & 3 & 3 & 3 & 3 & 3 \\
\hline 63 & 1 & 2 & 2 & 2 & 2 & 2 & 2 & 2 & 2 & 2 & 2 \\
\hline 64 & 1 & 1 & 1 & 1 & 1 & 1 & 1 & 1 & 1 & 1 & 1 \\
\hline
\end{tabular}

In the US, the safe-harbor plans, i.e. plans where employers are relieved from their fiduciary responsibility, are expected to have a diversified default fund that reduces the risk of large losses. The allocation should be in line with the risk appetite of its plan members. In Australia, specific governance requirements including the risk and the return from the plan's investments have to be taken into account by the trustees. The dynamic risk budget strategy has been designed with the perspective of managing the risk of loss given an individual's current risk budget.

A risk budget $\overline{\text { RiskBudget }}$ has been set for each one of the portfolio start allocations $i \in\{1, . ., 11\}$ (Table 6). It is determined by each plan member individually and is defined as the maximum loss that a portfolio can incur:

$$
\overline{\text { RiskBudget }_{i}}=\sum_{j=1}^{4} \omega_{j} \times \text { MaxLoss }_{j}
$$

where MaxLoss $_{j}$ and $\omega_{j}$ do respectively represent the maximum loss within a month and the initial weight of asset $j$ for the start allocation of portfolio $i$. A low risk budget will lead to defensive portfolios but also negative investment returns will lead to even more defensive portfolios to still meet the risk budget. 
Table D2. Risk budget set for each portfolio

\begin{tabular}{|c|c|c|c|c|c|c|c|c|c|c|c|}
\hline & $\begin{array}{c}\text { Portfolio } \\
1\end{array}$ & $\begin{array}{c}\text { Portfolio } \\
2\end{array}$ & $\begin{array}{c}\text { Portfolio } \\
3\end{array}$ & $\begin{array}{c}\text { Portfolio } \\
4\end{array}$ & $\begin{array}{c}\text { Portfolio } \\
5\end{array}$ & $\begin{array}{c}\text { Portfolio } \\
6\end{array}$ & $\begin{array}{c}\text { Portfolio } \\
7\end{array}$ & $\begin{array}{c}\text { Portfolio } \\
8\end{array}$ & $\begin{array}{c}\text { Portfolio } \\
9\end{array}$ & $\begin{array}{c}\text { Portfolio } \\
10\end{array}$ & $\begin{array}{c}\text { Portfolio } \\
11\end{array}$ \\
\hline $\begin{array}{l}\text { Risk } \\
\text { Budget }\end{array}$ & $10.9 \%$ & $13.1 \%$ & $15.7 \%$ & $17.5 \%$ & $19.3 \%$ & $21.3 \%$ & $23.5 \%$ & $25.7 \%$ & $28.0 \%$ & $30.2 \%$ & $32.4 \%$ \\
\hline
\end{tabular}

For a given start allocation $i \in\{3, . ., 9\}$, the current risk budget RiskBudget $_{i, t}$ will be calculated each month $t$ using the initial risk budget $\overline{\text { RiskBudget }}$, the floor $F_{i, t}$ and the portfolio value $V_{i, t}$.

$$
\text { RiskBudget }_{i, t}= \begin{cases}1-\frac{F_{i, t}}{V_{i, t}} & , \forall t>0 \\ \frac{\text { RiskBudget }_{i}}{} & , t=0\end{cases}
$$

The floor $F_{i, t}$ evolves with the following dynamics:

$$
F_{i, t}= \begin{cases}{\left[F_{i, t-1}+\left(1-\overline{\text { RiskBudget }_{i}}\right) \times \text { Contribution }_{t}\right] \times\left(1+r_{f_{t}}\right)} & , \forall t>0 \\ 0 & , t=0\end{cases}
$$

where the cash return is taken as the risk free rate $r_{f}$ used for the calculation of the floor.

The current risk budget will be compared each month with a given set of initial risk budgets representing the portfolios $Z_{i}=\{$ portfolio start allocation $\in[i-2 ; i+2]\}$. Then we choose the portfolio $z \in Z_{i}$ that minimizes the difference between $\overline{\text { RiskBudget }_{z}}$ and current RiskBudget $t_{i, t}$. The re-allocation process enables a maximum equity investment of $20 \%$ more than the initial equity allocation and a minimum equity investment of $20 \%$ less than the initial equity allocation. Thus only a limited number of portfolios are valid within the dynamic risk budget strategy.

For example, for the given start allocation of portfolio 5, only the portfolios 3, 4, 5, 6, 7 are valid in this policy. 
Figure D1. Dynamics of the dynamic risk budget investment strategy for the start allocation of portfolio 5

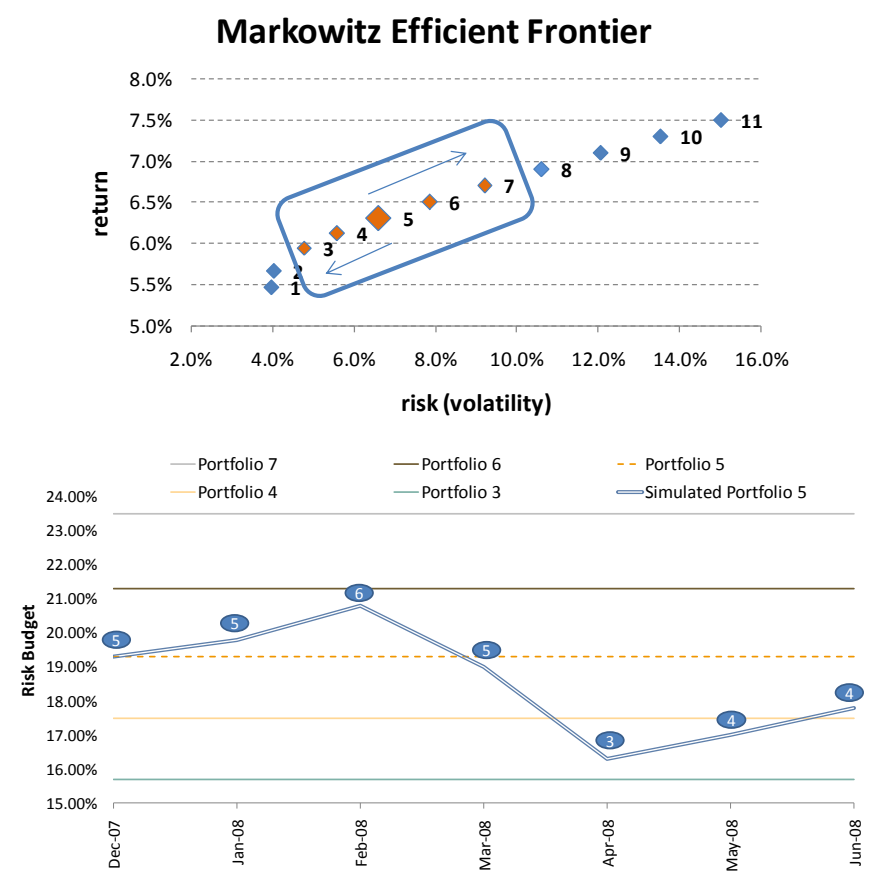

Concerning the portfolio start allocations $1,2,10$ and 11 , they are treated differently due to their location in the efficient frontier.

- For the start allocation of portfolio 1, only the portfolios 1, 2 and 3 are available in the strategy.

- For the start allocation of portfolio 2, only the portfolios 1, 2, 3 and 4 are available in the strategy.

- For the start allocation of portfolio 10 , only the portfolios $8,9,10$ and 11 are available in the strategy.

- For the start allocation of portfolio 11, only the portfolios 9, 10 and 11 are available in the strategy. 